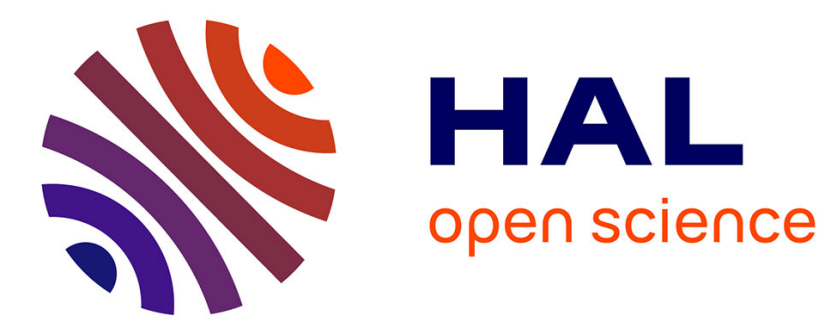

\title{
Serotonin is a novel survival factor of cardiomyocytes: mitochondria as a target of 5-HT 2B receptor signaling
}

Canan G Nebigil, Nelly Etienne, Nadia Messaddeq, Luc Maroteaux

\section{To cite this version:}

Canan G Nebigil, Nelly Etienne, Nadia Messaddeq, Luc Maroteaux. Serotonin is a novel survival factor of cardiomyocytes: mitochondria as a target of 5-HT 2B receptor signaling. FASEB Journal, 2003, 17 (10), pp.1373-1375. 10.1096/fj.02-1122fje . hal-01985091

\section{HAL Id: hal-01985091 \\ https://hal.science/hal-01985091}

Submitted on 17 Jan 2019

HAL is a multi-disciplinary open access archive for the deposit and dissemination of scientific research documents, whether they are published or not. The documents may come from teaching and research institutions in France or abroad, or from public or private research centers.
L'archive ouverte pluridisciplinaire $\mathbf{H A L}$, est destinée au dépôt et à la diffusion de documents scientifiques de niveau recherche, publiés ou non, émanant des établissements d'enseignement et de recherche français ou étrangers, des laboratoires publics ou privés. 
Serotonin is a novel survival factor of cardiomyocytes: mitochondria as a target of 5-HT $2 \mathrm{~B}^{-}$ receptor signaling

\title{
Running title: Serotonin in cardioprotection
}

Canan G. Nebigil, Nelly Etienne, Nadia Messaddeq, and Luc Maroteaux

Author affiliation: Institut de Génétique et de Biologie Moléculaire et Cellulaire, CNRS, INSERM, Université L. Pasteur de Strasbourg, BP 10142 - 67404 ILLKIRCH CEDEX - France;

Corresponding author: Luc Maroteaux, Institut de Génétique et de Biologie Moléculaire et Cellulaire, CNRS, INSERM, Université L. Pasteur de Strasbourg, BP 10142 - 67404 ILLKIRCH CEDEX - France

Tel: (33) 388653385 - Fax: (33) 3886532 01- E-mail\# lucm@igbmc.u-strasbg.fr

\begin{abstract}
Identification of factors regulating cardiomyocyte survival and growth is important to understand the pathogenesis of congenital heart diseases. Little is known about the molecular mechanism of cardiac functions triggered by serotonin. The link between signaling circuitry of external stimuli and the mitochondrial apoptotic machinery is of wide interest in cardiac diseases. Utilizing cultured cardiomyocytes and 5- $\mathrm{HT}_{2 \mathrm{~B}}$-receptor knockout mice as an animal model of dilated cardiomyopathy, for the first time we show that serotonin via the Gq-coupled 5- $\mathrm{HT}_{2 \mathrm{~B}}$-receptor protect cardiomyocytes against serum deprivation-induced apoptosis as manifested by DNA fragmentation, nuclear chromatin condensation and TUNEL labeling. Serotonin prevents cytochrome c release and caspase-9 and -3 activation following serum deprivation via cross talks between phosphatidylinositol3 kinase/Akt and ERK1/2 signaling pathways. Serotonin binding to 5-HT $2 \mathrm{~B}$-receptor activates ERK kinases to inhibit Bax expression induced by serum deprivation. Serotonin via phosphatidylinositol-3 kinase /Akt can activate NF-KB that is required for the regulation of the mitochondrial adenine nucleotide translocator (ANT-1). Parallel to these observations, ultrastructural analysis in the 5- $\mathrm{HT}_{2 \mathrm{~B}^{-}}$ receptor knockout mice heart revealed pronounced mitochondrial defects in addition to altered mitochondrial enzyme activities (cytochrome oxidase and succinate dehydrogenase), and ANT-1 and Bax expressions. These findings identify 5-HT as a novel survival factor targeting mitochondria in cardiomyocytes.
\end{abstract}

Key words: PI3Kinase/Akt/serotonin/Gq/ERK/Bax 


\section{Introduction}

Congenital heart disease is a major cause of disability and morbidity. Relatively little is known about the molecular mechanism of cardiac adaptation (hypertrophy) and maladaptation (apoptosis) underlying cardiac pathogenesis. Several lines of evidence suggest that serotonin (5hydroxytryptamine, 5-HT) is a neurohormone that regulates cardiovascular functions (50). 5-HT is secreted from enterochromaffin cells into the blood and stored in the platelets. Circulating 5-HT can also be taken up by sympathetic neurons and vascular endothelial cells and can be co-released (20). The various biological actions of 5-HT are mediated by numerous cognate receptors. It now appears that there are at least 15 receptor subtypes that belong to four classes: $5-\mathrm{HT}_{1 / 5}, 5-\mathrm{HT}_{2}, 5-\mathrm{HT}_{3}$, and 5$\mathrm{HT}_{4 / 6 / 7}$ (25). Binding of 5-HT to the Gq-coupled 5-HT $2 \mathrm{~A}, 5-\mathrm{HT}_{2 \mathrm{~B}}$ or $5-\mathrm{HT}_{2 \mathrm{C}}$-receptors activates phospholipase C (PLC), which initiates a rapid release of inositol trisphosphate and increases intracellular calcium levels. 5- $\mathrm{HT}_{2 \mathrm{~B}}$-receptor $\left(5-\mathrm{HT}_{2 \mathrm{~B}} \mathrm{R}\right)$ is involved in 5-HT-induced mitogenesis in which c-Src is required for cell cycle progression via the mitogen activated protein kinase (MAPK) pathway (42). Stimulation of the 5- $\mathrm{HT}_{2 \mathrm{~B}} \mathrm{R}$ results in cross talk with the $5-\mathrm{HT}_{1 \mathrm{~B} / 1 \mathrm{D}}$ receptor subtype via activation of phospholipase $\mathrm{A}_{2}(49)$. The $5-\mathrm{HT}_{2 \mathrm{~B}} \mathrm{R}$ also activates nitric oxide synthesis through a PDZ domain (34). We have recently shown that inactivation of the Gq-coupled 5-HT ${ }_{2 \mathrm{~B}} \mathrm{R}$ gene leads to partial embryonic and neonatal lethality due to the following defects in the heart: (i) 5- $\mathrm{HT}_{2 \mathrm{~B}} \mathrm{R}$ knockout embryos exhibit a lack of trabeculae defects leading to mid-gestation lethality. (ii) Newborn $5-\mathrm{HT}_{2 \mathrm{~B}} \mathrm{R}$ knockout mice exhibit cardiac dilation resulting from contractility deficits and structural deficits at the intercellular junctions between cardiomyocytes. (iii) In adult 5- $\mathrm{HT}_{2 \mathrm{~B}} \mathrm{R}$ knockout mice, echocardiography and electrocardiography confirm the presence of dilated cardiomyopathy (41).

In cultured cardiomyocytes and transgenic animal models, overexpression of Gq-coupled receptors or their signaling molecules, Gq, PLC or p38 MAPK triggers a hypertrophic response and/or extensive hypertrophy that leads to cardiomyocyte apoptosis $(3,35)$. On the other hand, several lines of evidence showed that circulating or locally released catecholamine and adenosine via their Gq-coupled receptors contribute to adaptive responses against hemodynamic stress or myocardial injury. Adenosine $\mathrm{A}(3)$ receptor activation limits myocardial injury in the isolated rat heart and improves survival in isolated cardiomyocytes, possibly by anti-apoptotic and anti-necrotic mechanisms (33). Stimulation of alpha-adrenergic receptors activates calcineurin leading to cardiac hypertrophy that protects against ischemia-reperfusion-induced cell death (13). Activation of alphaadrenergic receptors inhibits beta-adrenergic receptor induced apoptosis (28). Alpha-adrenergic receptor activation protects also cardiomyocytes against hypoxia and serum deprivation-induced apoptosis by regulating the expression of mitochondria-associated apoptosis regulatory genes, and activating hypertrophic growth (57). These reports indicated that activation of $\mathrm{Gq}$ signaling is important for protecting heart against various stresses. However, the molecular mechanisms involved are not known.

Mitochondria are an important component of the apoptotic signaling (31), especially in heart (22). In vitro apoptotic signals such as serum deprivation provoke release of cytochrome c (cytoC) from mitochondria to the cytoplasm. CytoC binds and activates Apaf-1, which in turn activates caspase-9 resulting in the culminating activation of caspase-3 $(7,24)$ that cleave key substrates during the apoptotic process (48). Several complex signal transduction pathways have been implicated in the execution of cardiomyocyte apoptosis including Ras, Raf, MAPK, (30), phosphatidylinositol-3 kinase (PI3K), and protein kinase B/Akt (54). Recently, the Bcl-2 gene family was shown as the central players of apoptosis regulation (2). Some members such as Bcl-2 and BclXL inhibit apoptosis while other such as Bax, Bad, and Bak, accelerate apoptosis by altering mitochondrial membrane permeability thereby inducing cytoC release. The link between signaling circuitry of external stimuli and the mitochondrial apoptotic machinery is of wide interest in cardiac diseases.

Although ablation of the Gq-coupled $5-\mathrm{HT}_{2 \mathrm{~B}} \mathrm{R}$ in mice leads to dilated cardiomyopathy (41), the functional role of $5-\mathrm{HT}_{2 \mathrm{~B}} \mathrm{R}$ in heart remains undefined. In this study, for the first time, we 
identified a cytoprotective 5- $\mathrm{HT}_{2 \mathrm{~B}} \mathrm{R}$ signaling linking membrane to mitochondrial apoptotic machinery utilizing in vitro and in vivo models.

\section{Materials and methods}

Material. 5-HT, PD-09858 and SB-206553 were purchased from R \& D Systems. SB-203580 and LY-294002 were purchased from Promega. Phospho-p44/p42 mitogen-activated protein kinase (MAPK), phospho-Akt, Akt, phospho-IKappaB and IKappaB (IKB) alpha antibodies were purchased from Cell Signaling Technology (Beverly, MA). Mouse MF-20 anti-myosin heavy chain antibody was purchased from Hybridoma Bank Laboratories. Anti-cytoC antibody was from BD Pharmingen. All other antibodies were purchased from Santa Cruz Biotechnology. Hoechst and Apoptag Tunel detection kit were from Boehringer Mannheim. All other reagents were purchased from Sigma.

Generation of 5-HT ${ }_{2 B} R$ knockout mice. Targeted mutagenesis by homologous recombination has been previously described (40). All animal experimentation was performed in accordance with institutional guidelines, and the French Animal Care Committee in accordance with European regulations approved protocols.

Cardiomyocyte isolation and transfection. Ventricular cardiomyocytes from neonatal mice (3-5 days old) were isolated by Percoll gradient technique as previously described (32). More than 95\% of cells exhibited specific myosin heavy chain (MHC)-positive cardiomyocytes staining. Cardiomyocytes were grown on plates precoated with fibronectin (Biocoat) in the medium (Dulbecco+ HamF-12) containing 10\% FCS and 5\% horse serum for overnight and cytosine arabinoside $(10 \mu \mathrm{M})$ was added to prevent proliferation of non-cardiomyocytes. The cells showed spontaneous contractility within $24 \mathrm{~h}$ after plating. For TUNEL analysis and for immunocytofluorescence experiments, cardiomyocytes were plated at a density of $10^{5}$ cells perLabTekTM glass slide chamber that were fibronectin coated. For Western analyses, cardiomyocytes were plated at a density of $2 \times 10^{6}$ cells per 35-mm fibronectin coated plastic culture dish.

For MAPK downregulation, cells were treated with mouse p42 and p44MAPK sense or antisense oligonucleotides $(30 \mu \mathrm{M})$ during $48 \mathrm{~h}$, then the medium was replaced by serum free medium (Dulbecco) for $24 \mathrm{~h}$ as described previously (42). Fluorescent-labeled synthetic phosphorothioate oligodeoxynucleotides that include the ATG initiation codon of mouse p42 and p44 MAPK mRNA, antisense (5'-GCCGCCGCCGCCGCCAT-3') or sense (5'-ATGGCGGCGGCGGCGGC-3') oligodeoxyribonucleotides were previously selected and tested for their efficiency (47). The efficiency of transfection was verified by Western blot and fluorescent microscopic analysis revealing that $\mathrm{p} 42$ and $\mathrm{p} 44 M A P K$ protein levels were reduced $80 \%$ in antisense oligonucleotide treated cells when compared to control or the sense.

DNA laddering. Visualization of apoptotic DNA fragments was performed as described (27). Briefly, after harvesting, cells were treated with lysis buffer $(10 \mathrm{mM}$ Tris- $\mathrm{HCl}, \mathrm{pH} 8,100 \mathrm{mM} \mathrm{NaCl}$, $25 \mathrm{mM}$ EDTA, $0.5 \%$ SDS and proteinase $\mathrm{K} 0,1 \mathrm{mg} / \mathrm{ml}$ ) and incubated at $50{ }^{\circ} \mathrm{C}$ for $4 \mathrm{~h}$. After DNA extraction, the purified DNA fragments were labeled with $\left({ }^{32} \mathrm{P}\right)$ ATP and separated by electrophoresis using a $2 \%$ agarose gel. The dried gel was exposed to Kodak X-Omat film.

Apoptosis determination by TUNEL analysis. TUNEL analysis of fragmented DNA was performed according to manufacturer's protocol as described before (56). Cells were treated with either agonists or antagonist for 4-6 days in serum free conditions. After 6 day of serum deprivation, no induction of endogenous anti-apoptotic factors was observed in cardiomyocytes. Cells then were fixed in $4 \%$ formaldehyde and permeabilized. After washing, slides were incubated with TdT terminal transferase and fluorescein-dUTP. Slides were counterstained with anti-MHC antibody and Hoechst. Cells were scored for TUNEL positive nuclei corresponding to condensed Hoechst stained nucleus. The percentage of TUNEL-positive cells was evaluated by viewing each field at x 60 magnification. Generally, 10 different microscopic fields containing 10-15 cells each were recorded for each sample. Each experiment was repeated at least three times. 
Cardiomyocyte virus infection. The adenovirus construct encoding dominant negative Akt (d3A-Akt) with a K179A/T308A/S473A mutation has been described before (21) and used on isolated cardiomyocytes. The adenovirus construct sIB encoding the IKB superactive form S32A/S36A was used as described before (10). Cardiomyocytes were plated in medium containing $10 \%$ FCS and 5\% horse serum overnight and then incubated with adenovirus vector at a multiplicity of infection of 35 in medium containing $2 \%$ FCS. After the overnight incubation, the virus was removed and cells were cultured in serum free medium. Infection efficiency was analyzed by GFP signaling using Adeno-GFP-infected cardiomyocytes, and is consistently $>80 \%$ by this method.

Extracellular Signal-Regulated Kinase (ERK) and Akt and IKB Activity Assay and Western Blot Analysis. MAPK activities were assayed by using phospho-p42/p44 MAPK (ERK1/2) antibodies (42). Stimulated cardiomyocytes were harvested in SDS sample buffer at various time points. Approximately $20 \mu \mathrm{g}$ of protein was separated on 10\% SDS/PAGE and blotted to nitrocellulose membranes. Two identical blots were incubated with antibody specific for the dually phosphorylated, activated forms of ERK1 and ERK2, and an antibody specific for ERK2 that is independent of its phosphorylation state. Similar Western blot analysis was performed using appropriate antibody for phospho-p38 or phospho-Akt or phospho-IKB alpha. Loading homogeneity was verified by stripping and reprobing the blots. Blots were stripped with $6.25 \mathrm{mM}$ Tris $\mathrm{pH} 7.5,2 \%$ SDS and $100 \mathrm{mM} 2-$ mercaptoethanol for $30 \mathrm{~min}$ at $45^{\circ} \mathrm{C}$, washed $1 \mathrm{~h}$ and reprobed with antisera specific for $\mathrm{p} 38$ or Akt or IKB antibodies.

Wild type and knockout cardiomyocytes were treated with serum free medium and $\pm 1 \mu \mathrm{M} 5$ HT or $\pm 5 \mathrm{nM}$ LIF for 4-6 days and then extracted and submitted to Western blot analyses to determine the cleavage of procaspase- 3 and procaspase- 9 as a indicator of relative activities using anti caspase-3 and caspase-9 antibodies. Cardiomyocytes were treated with serum free medium and $\pm 1 \mu \mathrm{M} 5$-HT and $\pm 10 \mu \mathrm{M}$ LY-294002, or $50 \mu \mathrm{M}$ PD-098059 for the indicated times and then extracted and submitted to Western blot analyses to determine the relative quantities of Bax and adenine nucleotide translocator (ANT-1) expression. Antibody-antigen complexes were detected with ECL kit according to manufacturer instruction. Densitometric analysis was carried out using Molecular Dynamics Image Quant software.

NF-KB Luciferase assays. Cells were transfected with plasmid coding for a luciferase driven by a minimal TK promoter upstream NF-KB responsive element. 24 hours after plating, cardiomyocytes were transfected with a plasmid pGL3-NFKB-RE-tk-luc mock (empty vector) utilizing transferrin transfection in combination with Fugene or Lipofectamine according to manufacturer recommendation (42). With this protocol, transfection efficiency in cardiomyocytes was measured by cotransfection of a B-Galactosidase-containing construct. Cells were stimulated with different concentration of 5-HT or LIF $(5 \mathrm{nM})$ for $24 \mathrm{~h}$. After cell lysis and removal of cell debris by centrifugation $150 \mu \mathrm{l}$ samples of cell lysate were combined with $50 \mu \mathrm{l}$ of luciferase buffer $(25 \mathrm{mM}$ Tris $\mathrm{pH}$ 7.8, 1 mM DTT, $15 \mathrm{mM} \mathrm{MgSO}_{4}, 4$ mM EDTA, $45 \mathrm{mM} \mathrm{KHPO}_{4} \mathrm{pH}$ 7.8, $0.3 \mathrm{mM}_{\text {luciferin, 5\% }}$ glycerol, $3 \mathrm{mM}$ ATP and $270 \mu \mathrm{M}$ Coenzyme A. An MGM Instruments Optolamp II luminometer was used to measure light emission of each sample for $5 \mathrm{sec}(12)$.

Analysis of cytosolic and mitochondrial fraction of cytoC. For cytosolic and mitochondrial fraction of cytoC, after cardiomyocyte treatment, cells were permeabilized, sampled on $12 \%$ SDS gel and processed for immunoblotting as described (18). In brief, cardiomyocytes were plated then suspended in $200 \mu \mathrm{l}$ of $0.025 \%$ digitonin (Calbiochem) in a lysis buffer ( $250 \mathrm{mM}$ sucrose,

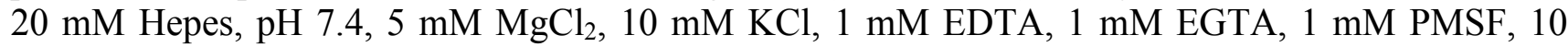
$\mathrm{mg} / \mathrm{ml}$ aprotinin, and $10 \mathrm{mg} / \mathrm{ml}$ leupeptin). After $10 \mathrm{~min}$, the cells were centrifuged (2 min, 13000 $\mathrm{rpm})$ and the supernatant was removed (cytosolic fraction). The remaining pellet was resuspended in $200 \mu \mathrm{l}$ mitochondrial lysis buffer $(150 \mathrm{mM} \mathrm{NaCl}, 1.0 \% \mathrm{NP}-40,0.5 \%$ triton-X-100, $50 \mathrm{mM}$ Tris-HCl, $\mathrm{pH}$ 8.0), lysis was allowed to proceed for a further $30 \mathrm{~min}$, and centrifuged. $28 \mu 1$ of each fraction was sampled on $12 \%$ SDS-PAGE. Densitometric analysis was performed with image analyzer (Bio-rad, GS-700). 
Immunostaining. Immunohistological detection was performed on isolated cardiomyocytes with antiserum against the anti-MHC antibody (MF-20), the cytoC, ANT-1, and Bax as previously described $(40,41)$. Signal intensity was quantified on digitalized images and calculated as the product of averaged pixel intensity per area. Densitometric analysis was carried out using Molecular Dynamics Image Quant software.

Morphological analysis of mouse heart. Transmission electron microscopy and histological techniques were performed as previously described (40, 41). For histochemistry, cryostat sections of heart $(7 \mu \mathrm{M})$ were fixed and blocked. The standard techniques were utilized for the immunohistochemistry.

Mitochondrial enzyme activity assay. The histochemical enzymatic test for succinate dehydrogenase and cytoC oxidase activities were performed on cryostat sections of unfixed heart from wild type and knockout mice as described (53).

Data analysis and statistics. All values represent average of independent experiments \pm S.E.M. ( $\mathrm{n}=$ number of experiments as indicated in the text). Comparisons between groups were performed using an ANOVA followed by a Student's t test. Significance was set at $\mathrm{p}<0.05$.

\section{Results}

5-HT via 5-HT ${ }_{2 B} R$ inhibits apoptosis induced by serum-deprivation in isolated cardiomyocytes

To evaluate the effect of 5-HT on cardiomyocyte survival, cardiomyocytes from neonatal heart were isolated and apoptosis was induced by serum deprivation. Apoptosis was detected first by monitoring internucleosomal cleavage with DNA laddering. DNA fragmentation was observed after the day 2 of serum deprivation and persisted throughout day 6 . Stimulation by $5-\mathrm{HT}(1 \mu \mathrm{M})$ or neuregulin (NRG-1, $25 \mathrm{ng} / \mathrm{ml}$ ) in the serum free condition protected wild type but not $5-\mathrm{HT}_{2 \mathrm{~B}} \mathrm{R}$ knockout cardiomyocytes from apoptosis as manifested with DNA fragmentation (Fig. 1A). To further confirm the role of $5-\mathrm{HT}_{2 \mathrm{~B}} \mathrm{R}$ in protecting cardiomyocyte from serum-deprivation induced apoptosis; we performed both TUNEL and Hoechst staining. As shown on figure 1B, apoptotic cardiomyocytes exhibited small-condensed nuclei detected by Hoechst staining (blue) corresponding to the TUNEL staining (green). A quantitative analysis revealed that cardiomyocytes subjected to serum free medium for 4-6 days displayed an approximate 38\% increase in apoptosis (Fig. 1C). In the presence of 5-HT or NRG-1 (not shown) for 4-6 days, the number of TUNEL-positive cardiomyocytes declined to $8 \pm 5 \%$. In the presence of specific $5-\mathrm{HT}_{2 \mathrm{~B}} \mathrm{R}$ inhibitor, $\mathrm{SB}-206553(1 \mu \mathrm{M})$, 5-HT was not able to inhibit apoptosis (Fig. 1C). Conversely, the 5-HT ${ }_{2 \mathrm{~B}} \mathrm{R}$ knockout cardiomyocytes exhibited an approximate 45\% apoptotic cells 4-6 days after serum deprivation and still displayed $46 \pm 5 \%$ apoptotic cells in the presence of 5-HT (Fig. 1C). These data indicate that 5-HT via 5-HT ${ }_{2 \mathrm{~B}} \mathrm{R}$ protects cardiomyocytes from apoptosis.

\section{PI3K/Akt and ERK1/2 activities cross talks in the anti-apoptotic pathway of 5-HT.}

To investigate the potential roles of the p38, Akt, or ERK pathways in 5-HT-mediated cytoprotection, cardiomyocytes were incubated with various cell-permeable inhibitors of these pathways in the presence and absence of 5-HT $(1 \mu \mathrm{M})$. Under these conditions, PD-098059 $(50 \mu \mathrm{M})$ a specific inhibitor of MEK1/2, and thus ERK (17), compromised the ability of 5-HT to protect the cardiomyocytes, resulting in about two times more apoptotic cells than observed in cells treated with 5-HT alone (from $8 \%$ in presence of 5-HT to $16 \%$ in presence of 5-HT plus PD-098059). Moreover, MAPK downregulation by transfecting cells with MAPK (ERK1/ERK2) antisense oligonucleotides blocked 5-HT cytoprotective effect to nearly the same extent as seen in the PD-098059 treated cells. LY-294002 (10 $\mu \mathrm{M})$, a specific inhibitor of PI3K, and thus Akt (37), also reduced the cytoprotective effects of 5-HT, resulting in about three times more apoptotic cells than observed in cells treated with 5-HT alone (24\% of apoptotic cells) (Fig. 2). Accordingly, a dominant negative d3A-Akt with 
K179A/T308A/S473A mutations reversed 5-HT-cytoprotective effect observed with LY-294002 at a similar efficiency. p38 inhibition by SB-203580 $(10 \mu \mathrm{M})$ had no effect on the 5-HT ${ }_{2 \mathrm{~B}} \mathrm{R}$-dependent cytoprotective effect of 5-HT in the wild type cardiomyocytes (data not shown). 5-HT-mediated cytoprotective effect was completely reversed in the presence of both PD-098059 and LY-294002. These results show that the cytoprotective effects conferred by 5-HT against serum deprivationinduced apoptosis are not only dependent upon ERK but also PI3K/Akt pathways.

Since inhibition of the PI3K/Akt and ERK pathways compromised the cytoprotective effects of 5-HT, the ability of the 5-HT to activate these pathways was evaluated using antibodies specific for each kinase at the residues that are phosphorylated upon activation. The relative level of phosphoERK1/2 was time-dependent and reached a maximum value of about 2-fold over control following 10 min of exposure to $1 \mu \mathrm{M} 5$-HT without altering total ERK-2 level (Fig. 3A). Phosphorylation of ERK1/2 by 5 -HT was blocked by $50 \mu \mathrm{M}$ PD-098059 (Fig. 3A-C). In 5-HT ${ }_{2 \mathrm{~B}} \mathrm{R}$ knockout cardiomyocytes, 5-HT was not able to activate ERK1/2. However, leukemia inhibitory factor (LIF, 5 $\mathrm{nM}$ ), a known survival factor still phosphorylates ERK1/2 in the 5- $\mathrm{HT}_{2 \mathrm{~B}} \mathrm{R}$ knockout cardiomyocytes. The levels of phospho-Akt (ser 473 and thr 308) were maximal following 15 min of exposure to 5-HT and amounted to about 3-fold over control (Fig 3B). Phosphorylation of Akt was blocked by $10 \mu \mathrm{M}$ LY-294002 but not by $50 \mu \mathrm{M}$ PD-098059 without altering total Akt expression (Fig. 3C). Both ERK and Akt were transiently activated by 5-HT or LIF. Moreover, no p38 phosphorylation in response to 5-HT could be evidenced (not shown), confirming that p38 activation is not involved in 5-HTdependent cytoprotection. These results are consistent with roles for ERK1/2 and Akt signaling pathways in $5-\mathrm{HT}_{2 \mathrm{~B}} \mathrm{R}$-mediated cytoprotection against serum deprivation-induced apoptosis.

\section{5-HT via 5-HT ${ }_{2 B} R$ activates the IKB-alpha/NF-KB signaling pathway}

To investigate the downstream regulators of ERK1/2 and PI3K/Akt kinase in cardiomyocytes, the effect of 5-HT on the activation of NF-KB was assessed using NF-KB/luciferase responsive element reporter gene. 5-HT stimulated NF-KB (Rel A)-dependent reporter transcription in wild type cardiomyocytes, while in 5- $\mathrm{HT}_{2 \mathrm{~B}} \mathrm{R}$ knockout cardiomyocytes, LIF but not 5-HT induced NF-KB activity (Fig. 4A). NF-KB staining in cardiomyocytes, initially localized in the cytoplasm in a punctuate pattern, was strikingly increased in the nucleus after $15 \mathrm{~min}$ of 5-HT treatment (Fig. 4B). Subsequently, IKB-alpha phosphorylation in the presence of 5-HT was determined. 5-HT phosphorylated IKB-alpha reaching to maximum at $15 \mathrm{~min}$ (data not shown). Indeed, phosphorylated form of IKB-alpha undergoes gradual degradation at $15 \mathrm{~min}$ (Fig. 4C). The time for nuclear translocation of NF-KB by 5-HT is consistent with the IKB-alpha degradation (Fig 4B). This phosphorylation of IKB-alpha by 5-HT was completely inhibited by the PI3K inhibitor LY-294002 but not by MAPK inhibitor PD-098059 (Fig. 4C). These results show that in cardiomyocytes 5-HT via PI3K/Akt induces IKB-alpha degradation thereby NF-KB nuclear translocation, which activates NF-KB-dependent gene transcription.

\section{5-HT via 5-HT $T_{2 B} R$ prevents cytoC redistribution and caspase cleavage in cardiomyocytes}

Next, we investigated the targets of 5-HT signaling for protecting cardiomyocytes from apoptosis. In wild type cardiomyocytes, cytoC was localized in the mitochondrial fraction, and no cytoplasmic cytoC was observed (Fig. 5A). However, the cytoC was substantially translocated from mitochondria to cytosol after serum deprivation. The mitochondrial release of cytoC into the cytoplasmic fraction was blocked after treatment of wild type cardiomyocytes with 5-HT $(1 \mu \mathrm{M})$ and LIF (5 nM). In 5- $\mathrm{HT}_{2 \mathrm{~B}} \mathrm{R}$ knockout cardiomyocytes, basal cytoplasmic cytoC was slightly increased and after serum deprivation, cytoplasmic cytoC reached to the maximum that was also observed in wild type cardiomyocytes. Conversely, 5-HT did not prevent cytoC translocation from mitochondria to cytosol, whereas LIF totally prevent this translocation in the 5- $\mathrm{HT}_{2 \mathrm{~B}} \mathrm{R}$ knockout cardiomyocytes 
(Fig. 5A). The total cytoC levels in wild type and 5- $\mathrm{HT}_{2 \mathrm{~B}} \mathrm{R}$ cardiomyocytes were similar. These data indicate that only 5-HT-mediated survival effects are impaired in 5- $\mathrm{HT}_{2 \mathrm{~B}} \mathrm{R}$ knockout cardiomyocytes.

Recent studies have demonstrated that release of cytoC from mitochondria leads to activation of caspase cascade in cardiomyopathic heart $(4,38)$. We examined the effect of 5-HT on caspase cleavage as an indicator of caspase activity. A significant increase in cleaved caspase- 3 and caspase- 9 was observed after serum -deprivation whereas the cleavage was negligible after the 5-HT treatment in wild type cardiomyocytes. No 5-HT-dependent but LIF-dependent inhibition of caspase-3 and caspase-9 cleavage was observed in 5- $\mathrm{HT}_{2 \mathrm{~B}} \mathrm{R}$ knockout cardiomyocytes (Fig. 5B).

These data indicate that $5-\mathrm{HT}$ via $5-\mathrm{HT}_{2 \mathrm{~B}} \mathrm{R}$ prevents cytoC redistribution from mitochondria thereby inhibiting caspase activity to protect cardiomyocytes from serum deprivation induced apoptosis.

\section{5-HT via 5-HT $T_{2 B}$ R regulates Bax and ANT-1 expression}

Next we investigated how 5-HT cytoprotective signaling prevents cytoC redistribution from mitochondria. The intrinsic mitochondria-dependent apoptotic pathway in cardiomyocytes is largely dependent on anti-apoptotic and pro-apoptotic members of the Bcl-2 family proteins. Bcl-2 inhibits apoptosis by blocking the release of cytoC from mitochondria during cellular stress whereas proapoptotic member Bax causes cytoC release (1). We investigated whether 5-HT regulates Bax expression thereby controlling cytoC release in isolated cardiomyocytes. In the apoptotic conditions, Bax expression increased 2 fold that was reduced in the presence of 5-HT. The effect of 5-HT was to downregulate Bax expression that was completely prevented by ERK1/2 inhibitor, PD-098059 (Fig. 6A). When the same blot was revealed with anti-phospho-Bad antibody no significant difference was observed in the Bad level or phosphorylation stage. These effects of 5-HT were completely absent in $5-\mathrm{HT}_{2 \mathrm{~B}} \mathrm{R}$ knockout cardiomyocytes. However, inhibition of PI3K by LY-294002 or inhibition of NF$\mathrm{KB}$ by the adenovirus sIB encoding the IKB superactive form S32A/S36A did not change 5-HTmediated regulation of Bax expression (Fig. 5A-6A). These data indicate that, in the cardiomyocytes, ERK1/2 activation by 5-HT is involved in regulating Bax expression, whereas PI3K/Akt did not alter Bax levels.

Next, we asked if PI3K/NF-KB signaling regulates also the mitochondrial membrane permeability. ANT-1 is a component of mitochondrial membrane permeability transition pore (14) and the only mitochondrial carrier for ADP and ATP. Since ANT-1 plays an important role in the disturbed cardiomyocyte metabolism in the dilated cardiomyopathy and ANT-1 mutant mice exhibited severe cardiomyopathy (23), we investigated possible regulation of ANT-1 in 5-HT cytoprotective signaling. In the apoptotic conditions, ANT-1 expression was increased in the wild type cardiomyocytes that was reduced in the presence of 5-HT. Downregulation of ANT-1 by 5-HT was completely inhibited by PI3K inhibitor LY-294002 but not by ERK1/2 inhibitor, PD-098059 (Fig. 6B). When NF-KB was blocked with the adenovirus sIB encoding the superactive IKB, the 5HT effect on ANT-1 expression was completely inhibited (Fig. 6B).

In vivo immunodetection of Bax and ANT-1 analysis in the frozen sections of the hearts showed that the Bax and ANT-1 levels were increased by $59 \pm 5$ and $38.9 \pm 4 \%$ respectively in the knockout mice heart (Fig. 6B). These results were confirmed by RT-PCR analysis (not shown). Our in vivo and in vitro data indicate that $5-\mathrm{HT} / 5-\mathrm{HT}_{2 \mathrm{~B}} \mathrm{R}$ cytoprotective signaling targets mitochondria by regulating Bax and ANT-1 expression and that 5-HT-cytoprotective signaling is impaired in the 5$\mathrm{HT}_{2 \mathrm{~B}} \mathrm{R}$ knockout mice heart.

\section{functions}

The 5-HT $T_{2 B}$ R knockout mice heart demonstrates abnormal mitochondrial structure and

Next we investigated the mitochondrial structure in the 5- $\mathrm{HT}_{2 \mathrm{~B}} \mathrm{R}$ knockout mice heart. Electron microscopic analysis in neonatal (Fig. 7A) and 6 weeks old (Fig. 7B) 5-HT ${ }_{2 \mathrm{~B}} \mathrm{R}$ knockout mice heart revealed pronounced mitochondrial abnormalities such as interrupted inner membrane, and swollen cristae. Although damage in mitochondria is a key step leading to programmed cell death, no 
ultrastructural nuclear fragmentation but myofibrillar breakdown was observed in the 5-HT ${ }_{2 \mathrm{~B}} \mathrm{R}$ knockout mice heart. To investigate how these structural abnormalities are reflected in the in vivo functions of mitochondria, enzymatic histochemical staining for cytoC oxidase (COX-2) and succinate dehydrogenase (SDH) activity were performed. These staining revealed reduced activity of both $\mathrm{SDH}$ and COX-2 by $40 \pm 5$ and $55 \pm 4 \%$ respectively in the $5-\mathrm{HT}_{2 \mathrm{~B}} \mathrm{R}$ knockout mice heart (Fig. 7B). These data indicate that secondary to structural defect in mitochondria of $5-\mathrm{HT}_{2 \mathrm{~B}} \mathrm{R}$ knockout mice heart, the electron chain transport and oxidative phosphorylation were disturbed as observed in human dilated cardiomyopathy $(39,51)$.

\section{Discussion}

Although a number of signaling pathways that lead to dilated cardiomyopathy and heart failure have been discovered, the factors that mediate distinct forms of cardiac hypertrophy, apoptosis and survival are not yet elucidated. Utilizing cultured cardiomyocytes, and 5- $\mathrm{HT}_{2 \mathrm{~B}} \mathrm{R}$ knockout mice as a model of dilated cardiomyopathy, we demonstrate that $5-\mathrm{HT}_{2 \mathrm{~B}} \mathrm{R}$ signaling regulates mitochondrial structure and function thereby controlling apoptosis and myofibrillar organization in the heart.

Suppression of Apoptosis by 5-HT. Overexpression of Gq-coupled receptors or Gq protein itself in cardiomyocytes contributes to the development of hypertrophy and/or ultimate decompensation of cardiac hypertrophy leading to apoptosis $(3,16,55)$. On the other hand, evidence suggests that hormones such as angiotensin II, endothelin 1, norepinephrine and prostaglandin F2 alpha via their cardiac Gq-coupled receptors contribute to adaptive responses after hemodynamic stress or myocardial injury (15). However, the mechanism by which Gq-coupled receptors mediate survival effects has not been clearly elucidated. For the first time, our data show that 5-HT can protect cardiomyocytes from apoptosis following serum deprivation. This protective effect is specifically mediated by the Gq-coupled $5-\mathrm{HT}_{2 \mathrm{~B}} \mathrm{R}$ : the cytoprotective effect of 5-HT was completely blocked by a specific $5-\mathrm{HT}_{2 \mathrm{~B}} \mathrm{R}$ inhibitor in wild type cardiomyocytes, and absent in the $5-\mathrm{HT}_{2 \mathrm{~B}} \mathrm{R}$ knockout cardiomyocytes. Previously, neural crest cells have been shown to exhibit apoptosis following the treatment of embryos with a $5-\mathrm{HT}_{2 \mathrm{~B}} \mathrm{R}$ antagonist (8), supporting the survival role of 5HT.

Mechanisms of protective action of 5-HT. 5-HT protects cardiomyocytes from apoptosis by preventing of cytoC redistribution thereby inhibiting caspase- 3 and -9 activation. Our data indicate that in the 5-HT anti-apoptotic signaling, ERK1/2 and PI3K/Akt crosstalk to regulate cardiomyocyte survival. In the present study, inhibitors of MAPK efficiently blocked the activation of ERK1/2 by 5HT, but did not interfere with the function of PI3K/Akt indicating that these two signaling pathway are independent of each other. Our observations are consistent with previous findings showing that both MAPK and PI3K/Akt signaling pathways are essential for antiapoptotic action of both interleukin-5 and stem cell factor (26). The downstream targets of MAPK and PI3K/Akt were unclear in cardiomyocytes. For the first time, we show that 5-HT mediated PI3K/Akt signaling is involved in IKB- alpha/NF-KB activation. Previously, it has been shown that PDGF activates Akt that is directly involved in IKB/NF-KB activation (45). Akt is also involved in cardiotrophin activation of NF-KB (p65) and cytoprotection of cardiomyocytes. Our results indicate that Gq-coupled 5-HT ${ }_{2 \mathrm{~B}} \mathrm{R}$ activation leads to degradation of IKB- alpha and subsequent translocation of NF-KB (p50) to the nucleus where NF-KB can regulate anti-apoptotic gene expression.

Mitochondria are targets of 5-HT-mediated cytoprotection. CytoC release due to impaired mitochondria has been observed in several models of apoptosis in cardiomyocytes $(39,52)$, however the importance of mitochondria as a direct target for factors protecting cardiomyocytes from apoptosis has not been examined yet. Our findings demonstrate that the 5-HT-induced cardiomyocyte cytoprotection involves cross talks between PI3K and ERK1/2 pathways that lead to the regulation of ANT-1 and Bax expression to protect of mitochondrial membrane permeability and cytoC release. In human pancreatic cancer cells, MEK/ERK signaling pathway regulates the expression of Bcl-2, Bcl$\mathrm{XL}$, and Mcl-1 and promotes survival (6). While the Bcl-2 family of proteins, at least in part, controls 
the mitochondrial apoptosis, we demonstrate that only ERK1/2 inhibition can overturn 5-HT-induced down regulation of Bax in cardiomyocytes. Parallel to these in vitro findings, a robust increased expression of Bax was observed in the $5-\mathrm{HT}_{2 \mathrm{~B}} \mathrm{R}$ knockout mice heart. Bax forms membrane pores that control mitochondrial permeability and release cytoC (46). Bcl-2 and Bcl-XL inhibit formation of these pores, however, no alteration in the expression of these genes could be detected by RT-PCR analysis of the 5- $\mathrm{HT}_{2 \mathrm{~B}} \mathrm{R}$ knockout mice heart mRNA (data not shown). We observed that Bax expression level was regulated by ERK1/2 activation in the 5-HT cytoprotective signaling, but the mechanism by which ERK1/2 activation controls Bax expression remains to be investigated.

We also observed that PI3K/Akt signaling maintains the integrity of mitochondrial permeability via a mechanism that is distinct from regulating $\mathrm{Bcl}-2$ expression or $\mathrm{Bad}$ phosphorylation in cardiomyocytes (19). Moreover, our data show that PI3K/Akt/NF-KB controls mitochondrial membrane permeability by regulating the ANT-1 expression. ANT-1 is the only mitochondrial transport system for nucleotides, an important link for energy production and accumulation process. It plays an important role in the disturbed myocardial metabolism in the dilated cardiomyopathy. ANT-1 mutant mice exhibited severe cardiomyopathy (23). Impaired ANT-1 function and increased ANT-1 levels were observed in heart tissue from patients with dilated cardiomyopathy (43) and point mutations in ANT-1 gene have been reported in humans to generate genetic mitochondrial disease (29). ANT-1 overexpression leads to the phenotypic alteration of the apoptosis, i.e. collapsed mitochondrial membrane potential, cytoC release, caspase activation and DNA degradation (5). In the 5- $\mathrm{HT}_{2 \mathrm{~B}} \mathrm{R}$ knockout mice heart, elevated expression level of ANT-1 is detected and we present evidence that ANT-1 is a main target of PI3K/Akt/NF-KB signaling that controls mitochondrial permeability in the cardiomyocytes. Moreover, transgenic mice overexpressing 5- $\mathrm{HT}_{2 \mathrm{~B}} \mathrm{R}$ in the heart exhibit decreased ANT-1 levels in the heart (unpublished observation). If Bax and ANT-1 interact in cardiomyocytes is currently unknown.

Evidence of mitochondrial involvement for 5-HT-mediated cytoprotection in vivo. Mitochondrial dysfunction has been reported in human cardiac diseases including ischemic and nonischemic heart failure, myocardial infarction, arrhythmia and myocarditis (11). We also observed mitochondrial structural defects in the $5-\mathrm{HT}_{2 \mathrm{~B}} \mathrm{R}$ knockout mice heart by electron microscopy analysis. In the knockout mice heart, reduced SDH and COX-2 activities are indicative of altered functions of electron transport complexes II and IV, respectively. Increased lactate plasma levels in knockout mice confirmed this observation (not shown). Decreased oxidative phosphorylation and respiration that lead to lactate production have also been observed in mitochondrial myopathies of human and in other animal models for dilated cardiomyopathy (38)

Although damage in mitochondria is a key step leading to programmed cell death, no typical apoptotic bodies were observed in the $5-\mathrm{HT}_{2 \mathrm{~B}} \mathrm{R}$ knockout mice heart despite impaired myofibrillar structure (41). Knockout cardiomyocytes may be in the pre-apoptotic stage long before nuclear events became morphologically manifested in vivo. Activation of caspases by cytoC in the failing myocardium induces breakdown of contractile proteins, which constitute the basis of impaired systolic ventricular function without inducing nuclear apoptosis $(9,36)$. Increased troponin I plasma levels in knockout mice confirmed this observation (41). Accordingly, evidence of cytoC redistribution from mitochondria to cytoplasm and caspase activation without nuclear morphology of apoptosis has also been observed in idiopathic dilated cardiomyopathic in human heart (44). Our in vivo and in vitro data clearly show that $5-\mathrm{HT} / 5-\mathrm{HT}_{2 \mathrm{~B}} \mathrm{R}$ signaling targets mitochondria. Recently, we observed that transgenic mice overexpressing $5-\mathrm{HT}_{2 \mathrm{~B}} \mathrm{R}$ in the heart exhibit mitochondrial proliferation and hypertrophy in the ventricular wall (unpublished observations).

Summary. Our data for the first time shows that 5-HT binding to 5- $\mathrm{HT}_{2 \mathrm{~B}} \mathrm{R}$ activates both $\mathrm{PI} 3 \mathrm{~K} / \mathrm{Akt}$ and ERK kinases in cardiomyocytes to protect mitochondrial damage thereby preventing apoptosis (Fig. 8). 5-HT prevents cytoC release and caspase-9 and -3 activation following serum deprivation by inhibiting ANT-1 and Bax expression via cross talks between PI3K/Akt and ERK1/2 signaling pathways, respectively. The regulation of ANT-1 expression results from activation of NF$\mathrm{KB}$ via $\mathrm{PI} 3 \mathrm{~K} / \mathrm{Akt}$. Utilizing $5-\mathrm{HT}_{2 \mathrm{~B}} \mathrm{R}$ knockout mice as a model of dilated cardiomyopathy, we 
demonstrate that the Gq-coupled $5-\mathrm{HT}_{2 \mathrm{~B}} \mathrm{R}$ signaling regulates mitochondrial structure and function (Fig. 8).

\section{Acknowledgements}

We thank Dr. K. Niederreither for critical reading of the manuscript and for helpful discussions. We wish to acknowledge Dr. K. Walsh for the dominant negative Akt adenovirus, Drs. M.V.G. Latronico and G. Condorelli for the adenovirus expressing the mutant form of IKB and Dr. H. Gronenmeyer for GL3-NF-KB-Luc. We thank P. Hickel for excellent technical assistance. This work has been supported by funds from the Centre National de la Recherche Scientifique, the Institut National de la Santé et de la Recherche Médicale, the Hôpital Universitaire de Strasbourg, the Universite Louis Pasteur, and by grants from the Fondation de France, and the Association pour la Recherche contre le Cancer \# 9503, 7389. C. G. N. is supported by a fellowship from the Fondation pour la Recherche Médicale.

\section{References}

1. Adams, J. M., and Cory, S. (1998) The Bcl-2 protein family: arbiters of cell survival. Science 281, 1322-1326.

2. Adams, J. M., and Cory, S. (2001) Life-or-death decisions by the Bcl-2 protein family. Trends Biochem. Sci. 26, 61-66.

3. Adams, J. W., and Brown, J. H. (2001) G-proteins in growth and apoptosis: lessons from the heart. Oncogene 20, 1626-1634.

4. Adams, J. W., Pagel, A. L., Means, C. K., Oksenberg, D., Armstrong, R. C., and Brown, J. H. (2000) Cardiomyocyte apoptosis induced by Galphaq signaling is mediated by permeability transition pore formation and activation of the mitochondrial death pathway. Circ. Res. 87, 11801187.

5. Bauer, M. K., Schubert, A., Rocks, O., and Grimm, S. (1999) Adenine nucleotide translocase-1, a component of the permeability transition pore, can dominantly induce apoptosis. J. Cell Biol. 147, 1493-1502.

6. Boucher, M. J., Morisset, J., Vachon, P. H., Reed, J. C., Laine, J., and Rivard, N. (2000) MEK/ERK signaling pathway regulates the expression of $\mathrm{Bcl}-2, \mathrm{Bcl}-\mathrm{X}(\mathrm{L})$, and $\mathrm{Mcl}-1$ and promotes survival of human pancreatic cancer cells. J. Cell. Biochem. 79, 355-369.

7. Bratton, S. B., and Cohen, G. M. (2001) Apoptotic death sensor: an organelle's alter ego? Trends Pharmacol. Sci. 22, 306-315.

8. Choi, D.-S., Ward, S., Messaddeq, N., Launay, J.-M., and Maroteaux, L. (1997) 5-HT2B receptor-mediated serotonin morphogenetic functions in mouse cranial neural crest and myocardiac cells. Development $124,1745-1755$

9. Communal, C., Sumandea, M., de Tombe, P., Narula, J., Solaro, R. J., and Hajjar, R. J. (2002) Functional consequences of caspase activation in cardiac myocytes. Proc. Natl. Acad. Sci. USA 99, 6252-6256.

10. Condorelli, G., Morisco, C., Latronico, M. V., Claudio, P. P., Dent, P., Tsichlis, P., Frati, G., Drusco, A., Croce, C. M., and Napoli, C. (2002) TNF-alpha signal transduction in rat neonatal cardiac myocytes: definition of pathways generating from the TNF-alpha receptor. FASEB J. 16, 1732-1737.

11. Cook, S. A., and Poole-Wilson, P. A. (1999) Cardiac myocyte apoptosis. Eur. Heart J. 20, 16191629.

12. Craig, R., Wagner, M., McCardle, T., Craig, A. G., and Glembotski, C. C. (2001) The cytoprotective effects of the glycoprotein 130 receptor-coupled cytokine, cardiotrophin-1, require activation of NF-kappa B. J. Biol. Chem. 276, 37621-37629.

13. De Windt, L. J., Lim, H. W., Taigen, T., Wencker, D., Condorelli, G., Dorn, G. W., 2nd, Kitsis, R. N., and Molkentin, J. D. (2000) Calcineurin-mediated hypertrophy protects cardiomyocytes 
from apoptosis in vitro and in vivo: An apoptosis-independent model of dilated heart failure. Circ. Res. 86, 255-263.

14. Desagher, S., and Martinou, J. C. (2000) Mitochondria as the central control point of apoptosis. Trends Cell Biol. 10, 369-377.

15. Dorn, G. W., 2nd, and Brown, J. H. (1999) Gq signaling in cardiac adaptation and maladaptation. Trends Cardiovasc. Med. 9, 26-34.

16. Dorn, G. W., 2nd, Tepe, N. M., Lorenz, J. N., Koch, W. J., and Liggett, S. B. (1999) Low- and high-level transgenic expression of beta2-adrenergic receptors differentially affect cardiac hypertrophy and function in Galphaq- overexpressing mice. Proc. Natl. Acad. Sci. USA 96, 6400-6405

17. Dudley, D. T., Pang, L., Decker, S. J., Bridges, A. J., and Saltiel, A. R. (1995) A synthetic inhibitor of the mitogen-activated protein kinase cascade. Proc. Natl. Acad. Sci. USA 92, 76867689

18. Ekert, P. G., Silke, J., Hawkins, C. J., Verhagen, A. M., and Vaux, D. L. (2001) DIABLO promotes apoptosis by removing MIHA/XIAP from processed caspase 9. J. Cell Biol. 152, 483490.

19. Flusberg, D. A., Numaguchi, Y., and Ingber, D. E. (2001) Cooperative control of Akt phosphorylation, bcl-2 expression, and apoptosis by cytoskeletal microfilaments and microtubules in capillary endothelial cells. Mol. Biol. Cell 12, 3087-3094.

20. Frishman, W. H., and Grewall, P. (2000) Serotonin and the heart. Ann. Med. 32, 195-209

21. Fujio, Y., Nguyen, T., Wencker, D., Kitsis, R. N., and Walsh, K. (2000) Akt promotes survival of cardiomyocytes in vitro and protects against ischemia-reperfusion injury in mouse heart. Circulation 101, 660-667.

22. Gill, C., Mestril, R., and Samali, A. (2002) Losing heart: the role of apoptosis in heart disease--a novel therapeutic target? FASEB J. 16, 135-146.

23. Graham, B. H., Waymire, K. G., Cottrell, B., Trounce, I. A., MacGregor, G. R., and Wallace, D. C. (1997) A mouse model for mitochondrial myopathy and cardiomyopathy resulting from a deficiency in the heart/muscle isoform of the adenine nucleotide translocator. Nat. Genet. 16, 226-234.

24. Green, D. R., and Reed, J. C. (1998) Mitochondria and apoptosis. Science 281, 1309-1312.

25. Hoyer, D., Hannon, J. P., and Martin, G. R. (2002) Molecular, pharmacological and functional diversity of 5-HT receptors. Pharmacol. Biochem. Behav. 71, 533-554.

26. Huang, H. M., Huang, C. J., and Yen, J. J. (2000) Mcl-1 is a common target of stem cell factor and interleukin-5 for apoptosis prevention activity via MEK/MAPK and PI-3K/Akt pathways. Blood 96, 1764-1771.

27. Huang, P., and Plunkett, W. (1992) A quantitative assay for fragmented DNA in apoptotic cells. Anal. Biochem. 207, 163-167.

28. Iwai-Kanai, E., Hasegawa, K., Araki, M., Kakita, T., Morimoto, T., and Sasayama, S. (1999) alpha- and beta-adrenergic pathways differentially regulate cell type- specific apoptosis in rat cardiac myocytes. Circulation 100, 305-311

29. Kaukonen, J., Juselius, J. K., Tiranti, V., Kyttala, A., Zeviani, M., Comi, G. P., Keranen, S., Peltonen, L., and Suomalainen, A. (2000) Role of adenine nucleotide translocator 1 in mtDNA maintenance. Science 289, 782-785.

30. Kinoshita, T., Shirouzu, M., Kamiya, A., Hashimoto, K., Yokoyama, S., and Miyajima, A. (1997) Raf/MAPK and rapamycin-sensitive pathways mediate the anti-apoptotic function of p21Ras in IL-3-dependent hematopoietic cells. Oncogene 15, 619-627.

31. Kroemer, G., and Reed, J. C. (2000) Mitochondrial control of cell death. Nat. Med. 6, 513-519.

32. Kubalak, S., Doevendans, P. A., Rockman, H. A., Hunter, J. J., Tanaka, N., Ross, J., and Chien, K. R. (1996) In Methods in Molecular Genetics Vol. 8 pp. 470-487 
33. Maddock, H. L., Mocanu, M. M., and Yellon, D. M. (2002) Adenosine A(3) receptor activation protects the myocardium from reperfusion/reoxygenation injury. Am. J. Physiol. 283, H13071313.

34. Manivet, P., Mouillet-Richard, S., Callebert, J., Nebigil, C. G., Maroteaux, L., Hosoda, S., Kellermann, O., and Launay, J.-M. (2000) PDZ-dependent activation of nitric-oxide synthases by the serotonin 2B receptor. J. Biol. Chem. 275, 9324-9331

35. Molkentin, J. D., and Dorn, G. W. n. (2001) Cytoplasmic signaling pathways that regulate cardiac hypertrophy. Annu. Rev. Physiol. 63, 391-426.

36. Moretti, A., Weig, H. J., Ott, T., Seyfarth, M., Holthoff, H. P., Grewe, D., Gillitzer, A., BottFlugel, L., Schomig, A., Ungerer, M., and Laugwitz, K. L. (2002) Essential myosin light chain as a target for caspase-3 in failing myocardium. Proc. Natl. Acad. Sci. USA 99, 11860-11865.

37. Moule, S. K., Welsh, G. I., Edgell, N. J., Foulstone, E. J., Proud, C. G., and Denton, R. M. (1997) Regulation of protein kinase B and glycogen synthase kinase-3 by insulin and betaadrenergic agonists in rat epididymal fat cells. Activation of protein kinase B by wortmanninsensitive and -insensitive mechanisms. J. Biol. Chem. 272, 7713-7719.

38. Narula, J., Kolodgie, F. D., and Virmani, R. (2000) Apoptosis and cardiomyopathy. Curr. Opin. Cardiol. 15, 183-188.

39. Narula, J., Pandey, P., Arbustini, E., Haider, N., Narula, N., Kolodgie, F. D., Dal Bello, B., Semigran, M. J., Bielsa-Masdeu, A., Dec, G. W., Israels, S., Ballester, M., Virmani, R., Saxena, S., and Kharbanda, S. (1999) Apoptosis in heart failure: release of cytochrome c from mitochondria and activation of caspase-3 in human cardiomyopathy. Proc. Natl. Acad. Sci. USA 96, 8144-8149.

40. Nebigil, C. G., Choi, D.-S., Dierich, A., Hickel, P., Le Meur, M., Messaddeq, N., Launay, J.-M., and Maroteaux, L. (2000) Serotonin 2B receptor is required for heart development. Proc. Natl. Acad. Sci. USA 97, 9508-9513

41. Nebigil, C. G., Hickel, P., Messaddeq, N., Vonesch, J.-L., Douchet, M.-P., Monassier, L., György, K., Martz, R., Andriantsitohaina, R., Manivet, P., Launay, J.-M., and Maroteaux, L. (2001) Ablation of serotonin 5-HT2B receptors in mice leads to abnormal cardiac structure and function. Circulation 103, 2973-2979

42. Nebigil, C. G., Launay, J.-M., Hickel, P., Tournois, C., and Maroteaux, L. (2000) 5Hydroxytryptamine 2B receptor regulates cell-cycle progression: Cross talk with tyrosine kinase pathways. Proc. Natl. Acad. Sci. USA 97, 2591-2596

43. Portman, M. A. (2000) Adenine nucleotide translocator in heart. Mol. Genet. Metab. 71, 445450.

44. Reed, J. C., and Paternostro, G. (1999) Postmitochondrial regulation of apoptosis during heart failure. Proc. Natl. Acad. Sci. USA 96, 7614-7616.

45. Romashkova, J. A., and Makarov, S. S. (1999) NF-kappaB is a target of AKT in anti-apoptotic PDGF signalling. Nature 401, 86-90.

46. Saito, S., Hiroi, Y., Zou, Y., Aikawa, R., Toko, H., Shibasaki, F., Yazaki, Y., Nagai, R., and Komuro, I. (2000) beta-Adrenergic pathway induces apoptosis through calcineurin activation in cardiac myocytes. J. Biol. Chem. 275, 34528-34533.

47. Sale, E. M., Atkinson, P. G., and Sale, G. J. (1995) Requirement of MAP kinase for differentiation of fibroblasts to adipocytes, for insulin activation of p90 S6 kinase and for insulin or serum stimulation of DNA synthesis. EMBO J. 14, 674-684

48. Shi, Y. (2001) A structural view of mitochondria-mediated apoptosis. Nat. Struct. Biol. 8, 394401.

49. Tournois, C., Mutel, V., Manivet, P., Launay, J. M., and Kellermann, O. (1998) Cross-talk between 5-hydroxytryptamine receptors in a serotonergic cell line. Involvement of arachidonic acid metabolism. J. Biol. Chem. 273, 17498-17503

50. Villalon, C. M., de Vries, P., and Saxena, P. R. (1997) Serotonin receptors as cardiovascular targets. Drug Discovery Today 2, 294-300 
51. von Harsdorf, R., Hauck, L., Mehrhof, F., Wegenka, U., Cardoso, M. C., and Dietz, R. (1999) E2F-1 overexpression in cardiomyocytes induces downregulation of p21CIP1 and p27KIP1 and release of active cyclin-dependent kinases in the presence of insulin-like growth factor I. Circ. Res. 85, 128-136.

52. von Harsdorf, R., Li, P. F., and Dietz, R. (1999) Signaling pathways in reactive oxygen speciesinduced cardiomyocyte apoptosis. Circulation 99, 2934-2941.

53. Wang, J., Wilhelmsson, H., Graff, C., Li, H., Oldfors, A., Rustin, P., Bruning, J. C., Kahn, C. R., Clayton, D. A., Barsh, G. S., Thoren, P., and Larsson, N. G. (1999) Dilated cardiomyopathy and atrioventricular conduction blocks induced by heart-specific inactivation of mitochondrial DNA gene expression. Nat. Genet. 21, 133-137.

54. Wang, J. M., Chao, J. R., Chen, W., Kuo, M. L., Yen, J. J., and Yang-Yen, H. F. (1999) The antiapoptotic gene mcl-1 is up-regulated by the phosphatidylinositol 3-kinase/Akt signaling pathway through a transcription factor complex containing CREB. Mol. Cell. Biol. 19, 61956206.

55. Wettschureck, N., Rutten, H., Zywietz, A., Gehring, D., Wilkie, T. M., Chen, J., Chien, K. R., and Offermanns, S. (2001) Absence of pressure overload induced myocardial hypertrophy after conditional inactivation of Galphaq/Galpha11 in cardiomyocytes. Nat. Med. 7, 1236-1240.

56. Zechner, D., Craig, R., Hanford, D. S., McDonough, P. M., Sabbadini, R. A., and Glembotski, C. C. (1998) MKK6 activates myocardial cell NF-kappaB and inhibits apoptosis in a p38 mitogenactivated protein kinase-dependent manner. J. Biol. Chem. 273, 8232-8239.

57. Zhu, H., McElwee-Witmer, S., Perrone, M., Clark, K. L., and Zilberstein, A. (2000) Phenylephrine protects neonatal rat cardiomyocytes from hypoxia and serum deprivation-induced apoptosis. Cell Death Differ 7, 773-784. 
Legends to figures

\section{Nebigil Figure 1}

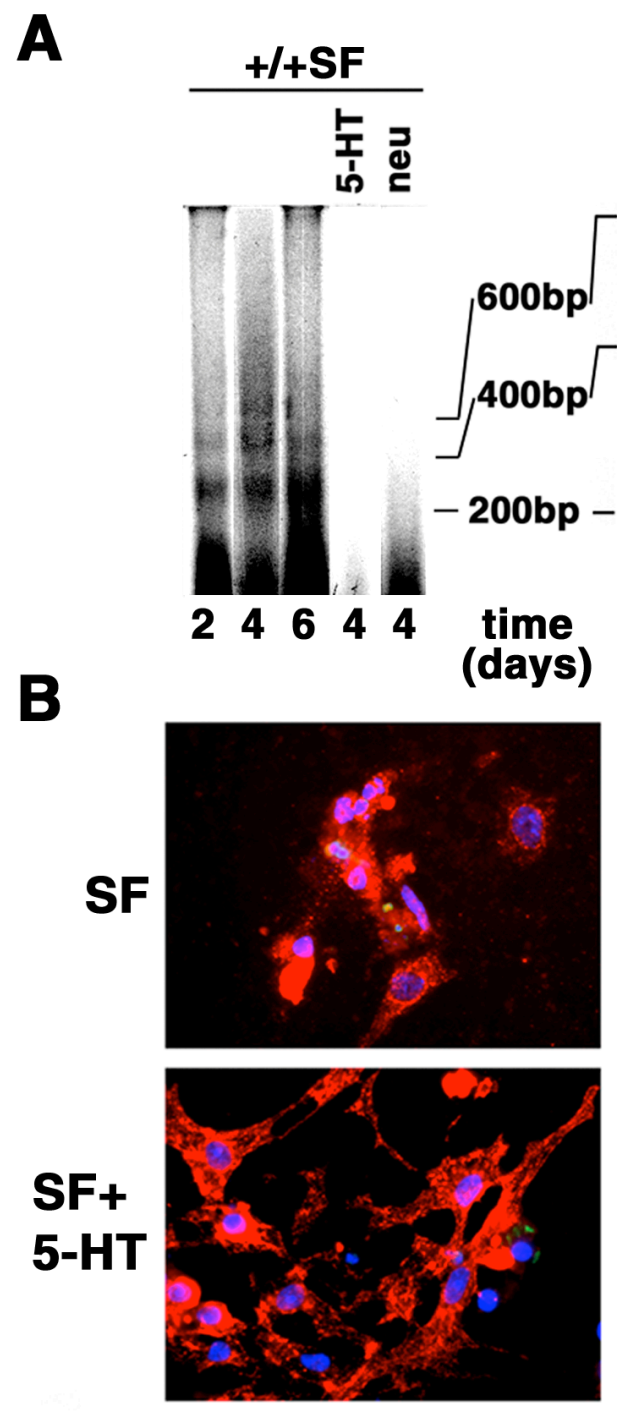

MHC
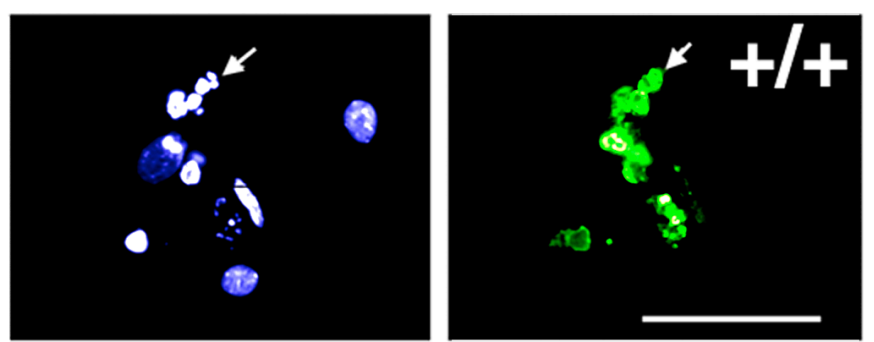

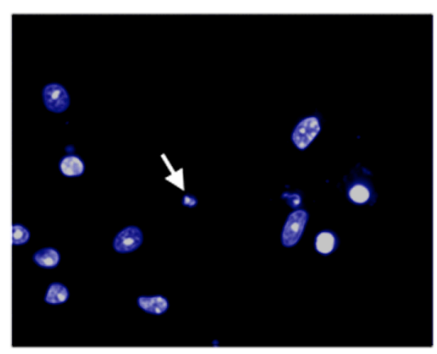

Hoechst

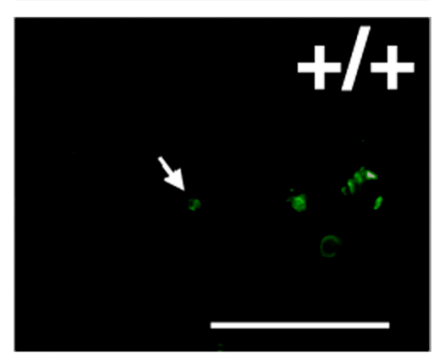

TUNEL

Figure 1. 5-HT via 5-HT ${ }_{2 B}$ R acts as a survival factor in cardiomyocytes A) 5-HT prevents DNA laddering induced by serum deprivation in isolated wild type cardiomyocytes. DNA laddering was observed from 2, 4, to 6 days of serum deprivation (SF). The effect of 5-HT $(1 \mu \mathrm{M})$ or neuregulin (NRG-1, $25 \mathrm{ng} / \mathrm{ml}$, neu) was studied by DNA laddering at 4 days of serum deprivation in wild type $(+/+)$ or knockout cardiomyocytes (-/-). The DNA size marker is in base pairs (bp). B) 5-HT prevents apoptosis induced by serum deprivation in wild type cardiomyocytes. Myocardial cells plated 4-6 days in serum-free (SF) media, $\pm 1 \mu \mathrm{M} 5$-HT or $\pm 1 \mu \mathrm{M}$ SB-206553 (SB), a specific $5-\mathrm{HT}_{2 \mathrm{~B}} \mathrm{R}$ receptor antagonist, were then fixed for TUNEL (green) analysis and Hoechst (blue) staining. MHC staining (red) shows the pure population of cultured cardiomyocytes. Illustrations show cardiomyocytes that are representative of the cell population observed following the treatments indicated above. White arrows indicate double stained, Hoechst and TUNEL positive cells with small and condensed nuclei. C) Quantitative analysis of TUNEL staining. The number of TUNEL-positive cells in each microscopic field was determined, as described in methods, and then normalized to the total number of cells in that field to obtain the numbers of TUNEL-positive cells as a percent of the total. Each value represents the mean of 10 separate fields $(\sim 15$ cells/field $) \pm$ S.E.M. $(P<0.05$, star $)$. These experiments are representative of three similar experiments. 


\section{Nebigil figure 2}
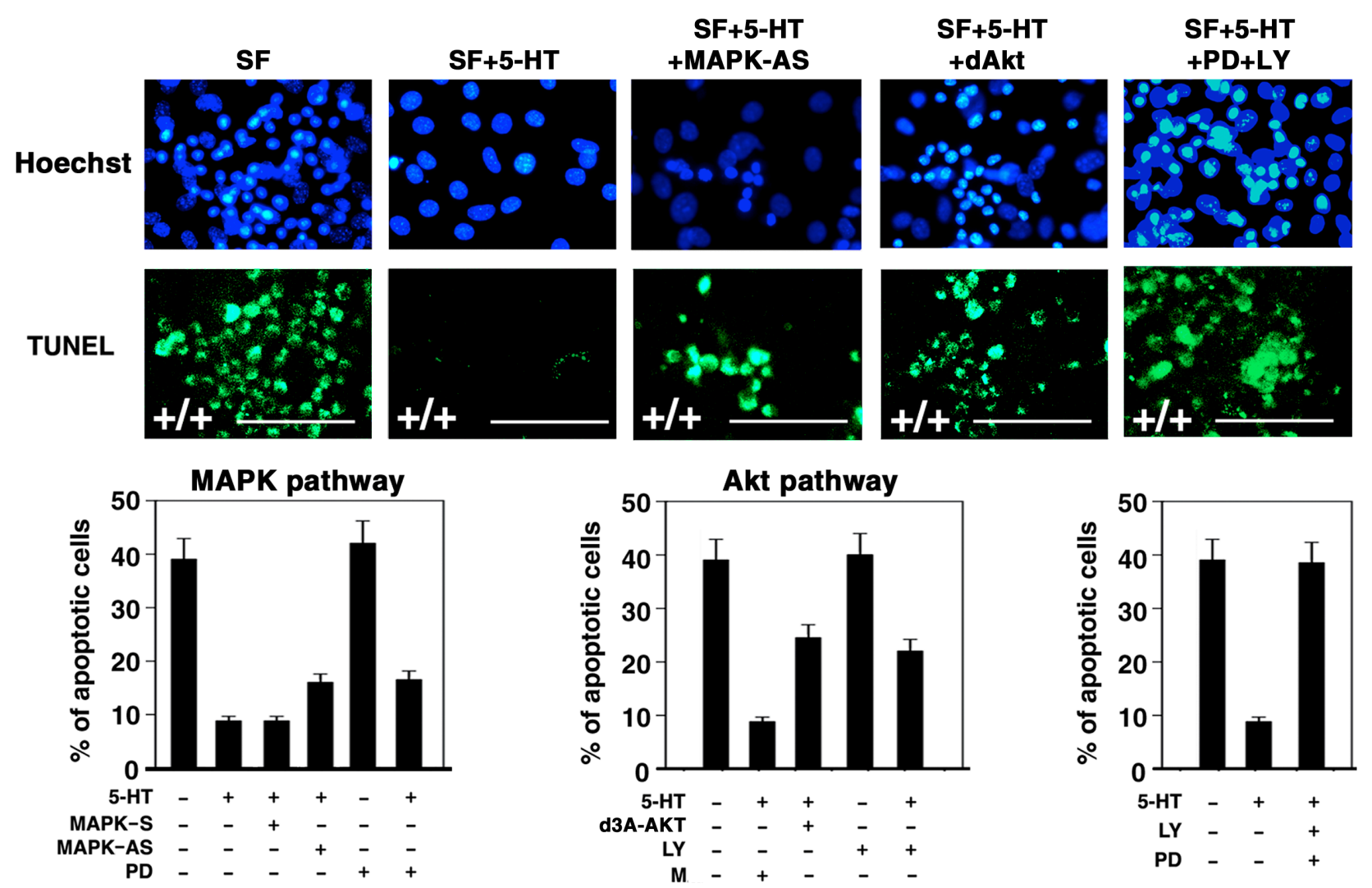

Figure 2. Effects of cell-permeable inhibitors and dominant negative signaling proteins on 5-HTmediated inhibition of apoptosis. Illustrations show wild type cardiomyocytes that are representative of the cell population following treatments inhibiting either MAPK or PI3K pathways. For MAPK inhibition, cardiomyocytes were treated in serum free (SF) conditions with $\pm 1 \mu \mathrm{M} 5$-HT and $\pm 50 \mu \mathrm{M}$ PD-098568 (PD). For MAPK downregulation, cells were treated with mouse p42 and p44 ${ }^{M A P K}$ sense (MAPKS) or antisense (MAPK-AS) fluorescent-labeled synthetic phosphorothioate oligodeoxynucleotides $(30 \mu \mathrm{M})$ during 48 hours, then in serum free medium for 24 hours, then with \pm 1 $\mu \mathrm{M} 5$-HT for 4 days. Expression levels of each protein were approximately equal, as determined by Western blot analysis (not shown). To inhibit Akt activity, similar experiment was performed with \pm 1 $\mu \mathrm{M} 5$-HT and $\pm 10 \mu \mathrm{M}$ LY-294002 (LY). To downregulate Akt, cardiomyocytes were plated in medium containing 10\% FCS and 5\% horse serum overnight and then incubated with adenovirus construct encoding a dominant negative Akt (d3A-AKT) with a K179A/T308A/S473A mutation in medium containing $2 \%$ FCS. After the overnight incubation, the virus was removed and cells were cultured in serum free medium (SF). Infection efficiency was evaluated by counting GFP positive cells using Adeno-GFP-infected cardiomyocytes. Each inhibitor trial was paired with its own control, 6 days after cells were fixed for TUNEL analysis. The number of TUNEL-positive cells in each microscopic field was determined, as described in methods and then normalized to the total number of cells in that field to obtain the numbers of TUNEL-positive cells as a percent of the total. Bars: $500 \mu \mathrm{m}$. Each value represents the mean of 10 separate fields $(\sim 150$ cells/field $) \pm$ S.E.M. These experiments are representative of three similar experiments. $M$ indicates mock transfection with the virus. 


\section{Nebigil figure 3}

A

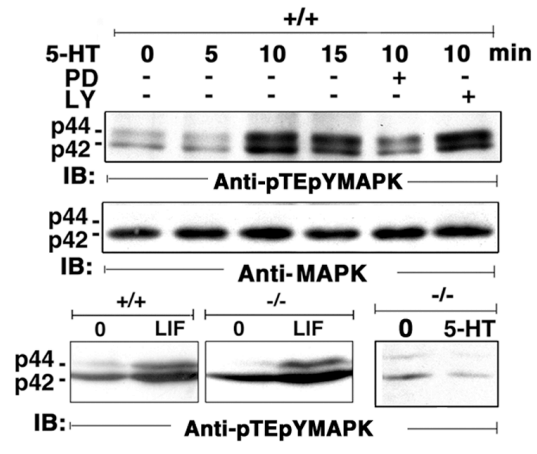

B
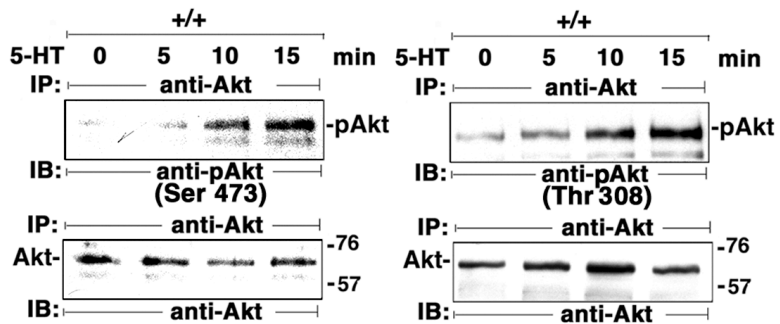
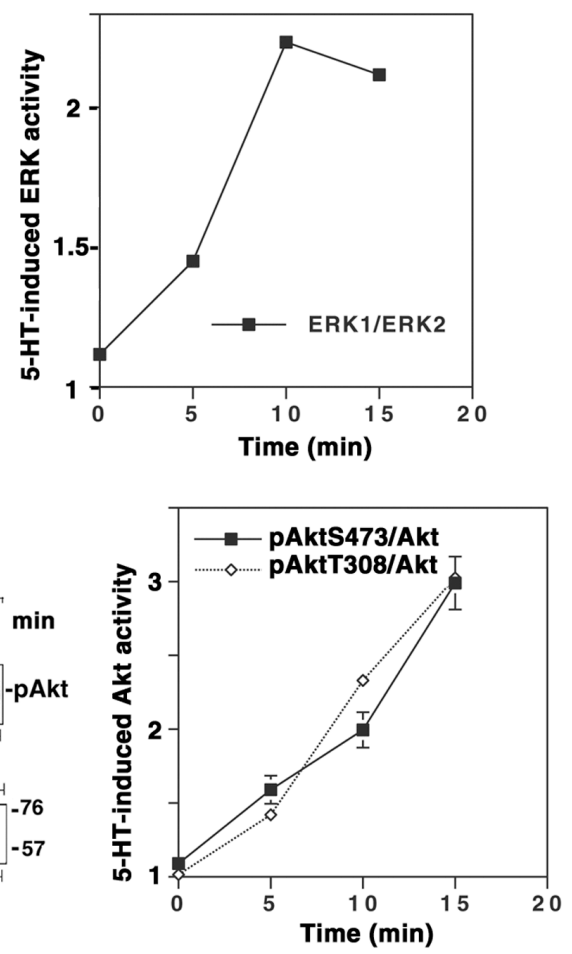

C
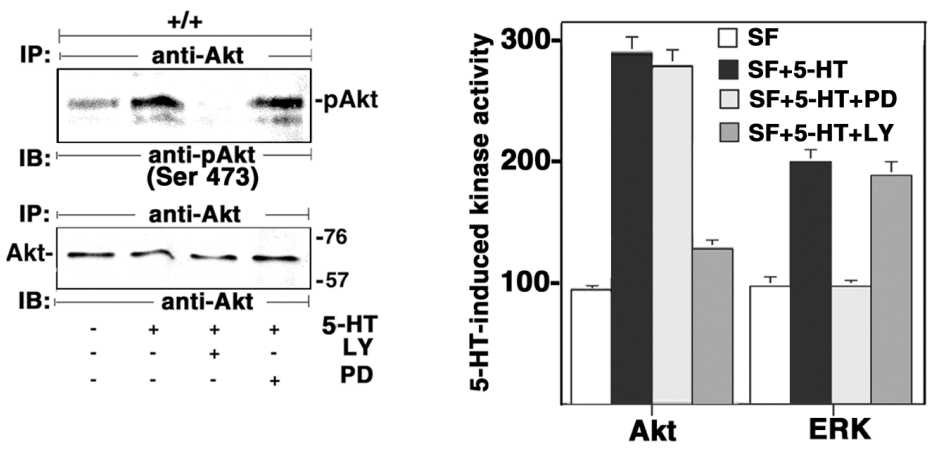

Figure 3. 5-HT activates ERK1/2 and Akt kinases. Cardiomyocytes were treated $\pm 1 \mu \mathrm{M}$ 5-HT and $10 \mu \mathrm{M}$ LY-294002 (LY), or $50 \mu \mathrm{M}$ PD-098059 (PD) for the indicated times, then extracted and submitted to Western blot analysis to determine the relative quantities of phosphorylated and total, Akt, or ERK, as described in methods. A) 5-HT increases ERK1/2 phosphorylation in a time-dependent manner. As revealed using anti-phospho- MAPK antibody (anti-pMAPK thr 202; tyr 204) (pTEpYMAPK), the ERK1/2 phosphorylation peaks at $10 \mathrm{~min}$ in wild type cardiomyocytes $(+/+)$ but not in knockout cardiomyocytes (-/-). Two identical blots were incubated with antibody specific for the dually phosphorylated, activated forms of ERK1 and ERK2, and an antibody specific for ERK2 that is independent of its phosphorylation state to verify samples homogeneity. ERK activation was evaluated in presence of 5-HT \pm PD-098059 or \pm LY-294002 and in presence of LIF in both wild type and knockout cardiomyocytes. B) 5-HT enhances Akt phosphorylation in a time dependent manner. As revealed with anti phospho-Akt antibodies (anti-pAkt ser 473 or anti-pAkt thr 308) Akt phosphorylation peaks at $15 \mathrm{~min}$ in wild type cardiomyocytes $(+/+)$. 5-HT does not modify the Akt expression as revealed by anti Akt antibody (anti-Akt) after blot restripping. C) Akt activation by 5-HT is completely blocked by LY-294002, but not by PD-098059. Akt activation by 5-HT was evaluated in presence of inhibitors LY-294002, or PD-098059. Quantification of these experiments presented in the graphs was determined using densitometry and Molecular Dynamics ImageQuant software and shown as average S.E.M.. IP: immunoprecipitation, IB: immunoblot. Blots are representative of 3 separate experiments. 


\section{Nebigil figure 4}
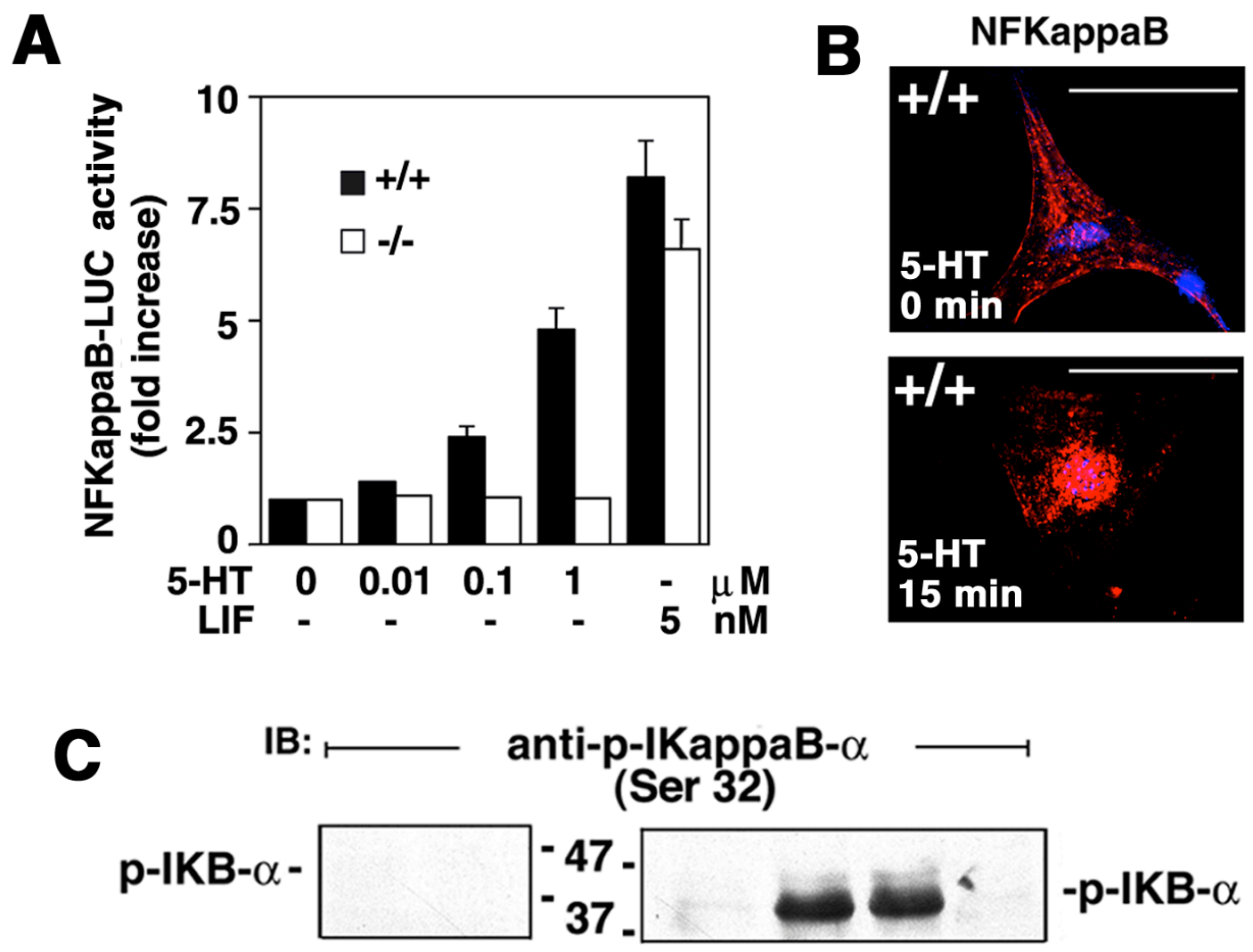

IB: $\longmapsto$ anti-IKappaB- $\alpha$

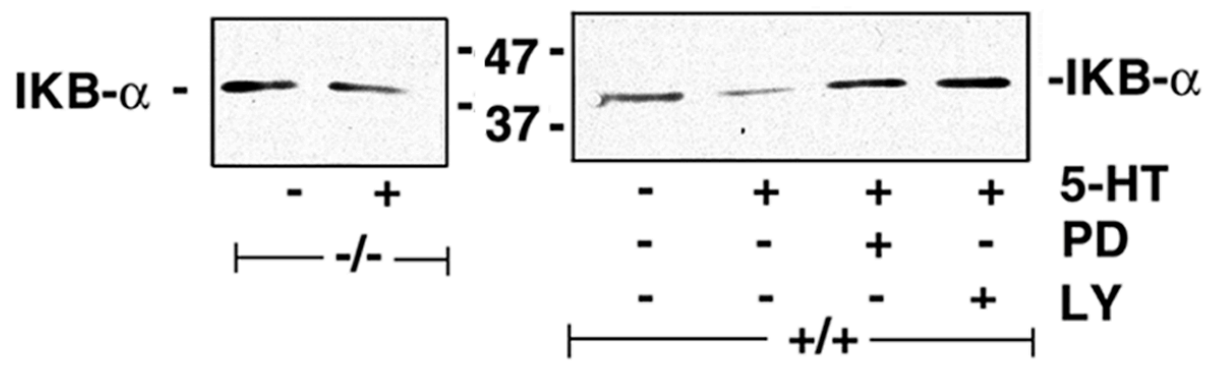

Figure 4. Effects of 5-HT on IKB degradation, NF-KB-mediated transcription and cellular localization. A) 5-HT activates NF-KB-mediated transcription. Wild type and knockout cardiomyocytes were co-transfected with an (pGL3-NF-KB-RE-tk-luc,12 $\mu \mathrm{g}$ ) and $B$-galactosidase reporter $(20 \mu \mathrm{g})$. Following 24 hours in serum-free medium (SF), the cells were treated for another 24 hours with serumfree medium \pm 5 -HT or LIF at the concentrations indicated, then extracted and assayed for luciferase and B-galactosidase activities as described in methods. This experiment is representative of three similar experiments. B) 5-HT induces p50/NF-KB nuclear translocation. Cardiomyocytes were incubated in serum-free media for 24 hours, treated $\pm 1 \mu \mathrm{M} 5$-HT for the indicated times and stained for p50/NF-KB (NFKappaB). Primary antibody localization was visualized using CY3-conjugated secondary antibody to show the localization of NF-KB after 5-HT treatment. Shown are single myocytes that are representative of the cell population following the treatments indicated. This experiment is representative of three similar experiments. Bars: $5 \mu \mathrm{m}$. C) 5-HT-mediated IKB phosphorylation is inhibited by PI3K inhibitor. Cardiomyocytes were treated in serum free medium with $\pm 1 \mu \mathrm{M} 5$-HT and $\pm 10 \mu \mathrm{M}$ LY-294002 (LY), or $\pm 50 \mu \mathrm{M}$ PD-098059 (PD) for 4 days, then extracted and submitted to Western blot analyses to determine the relative quantities of phosphorylated and total IKB after blot restripping. This experiment is representative of three similar experiments. 


\section{Nebigil Figure 5}

A
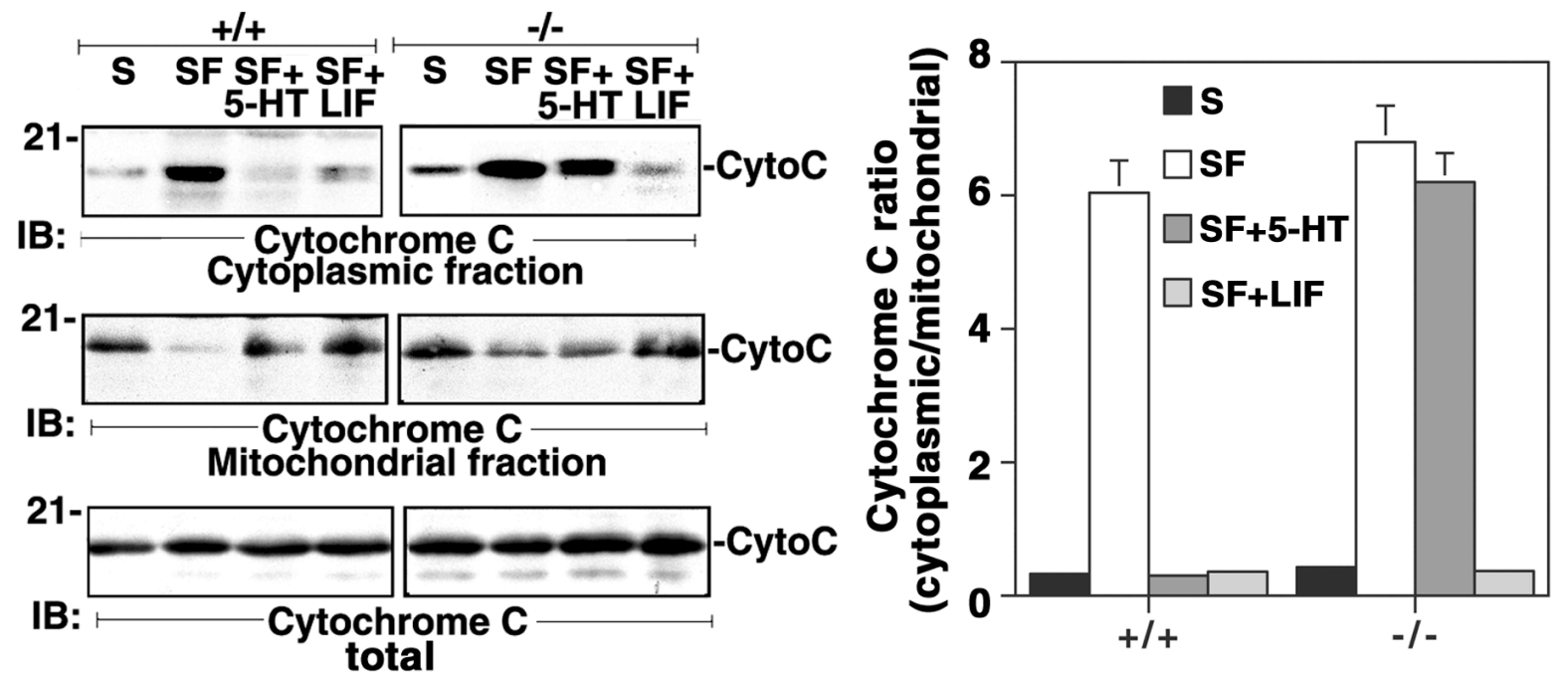

B

B
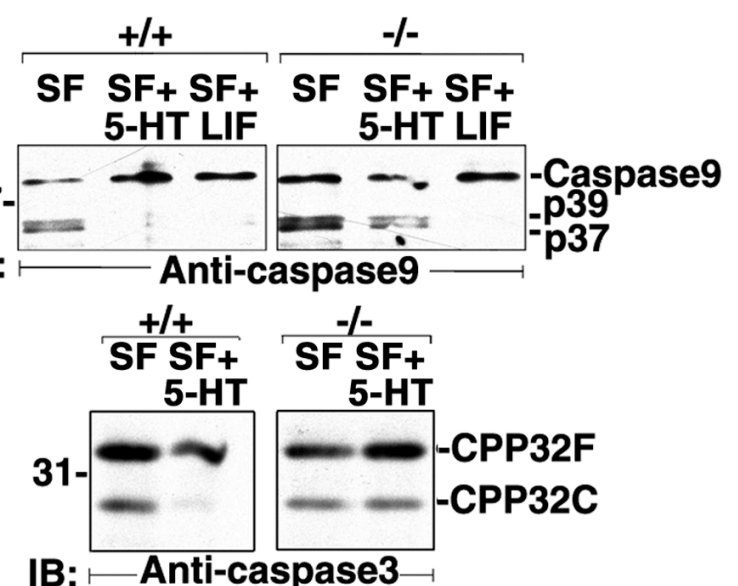

Figure 5. Effects of 5-HT on cytoC cellular localization. A) 5-HT prevents translocation of cytoC from mitochondria to cytosol in wild type cardiomyocytes. Wild type and in knockout cardiomyocytes were treated in serum (S), and serum free (SF) medium with $\pm 1 \mu \mathrm{M} 5$-HT or $\pm 5 \mathrm{nM}$ LIF, then mitochondrial and cytosolic fractions were extracted and submitted to Western blot analyses to determine the relative quantities of cytoC, as shown and as described in methods. IP: immunoprecipitation; IB: immunoblot. Blots are representative of 3 separate experiments. The values presented in the graphs were determined using densitometry and Molecular Dynamics ImageQuant software and shown as average S.E.M. B) 5-HT prevents caspase activation in wild type cardiomyocytes. Wild type and knockout cardiomyocytes were treated in serum free (SF) medium with $\pm 1 \mu \mathrm{M} 5$-HT or $\pm 5 \mathrm{nM}$ LIF for 4 days, then extracted and submitted to Western blot analyses to determine the cleavage of procaspase- 3 and procaspase- 9 as a indicator of relative activities using anti caspase-3 and caspase-9 antibodies. Procaspase-3; CPP32F, cleaved caspase-3; CPP32C, IB: immunoblot. This experiment is representative of three similar experiments. 
Nebigil Figure 6

A
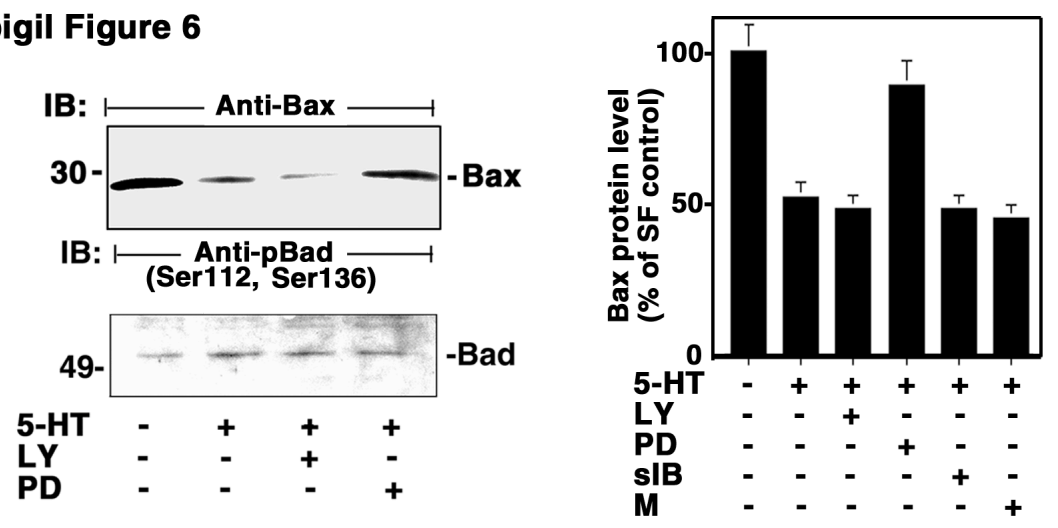

B
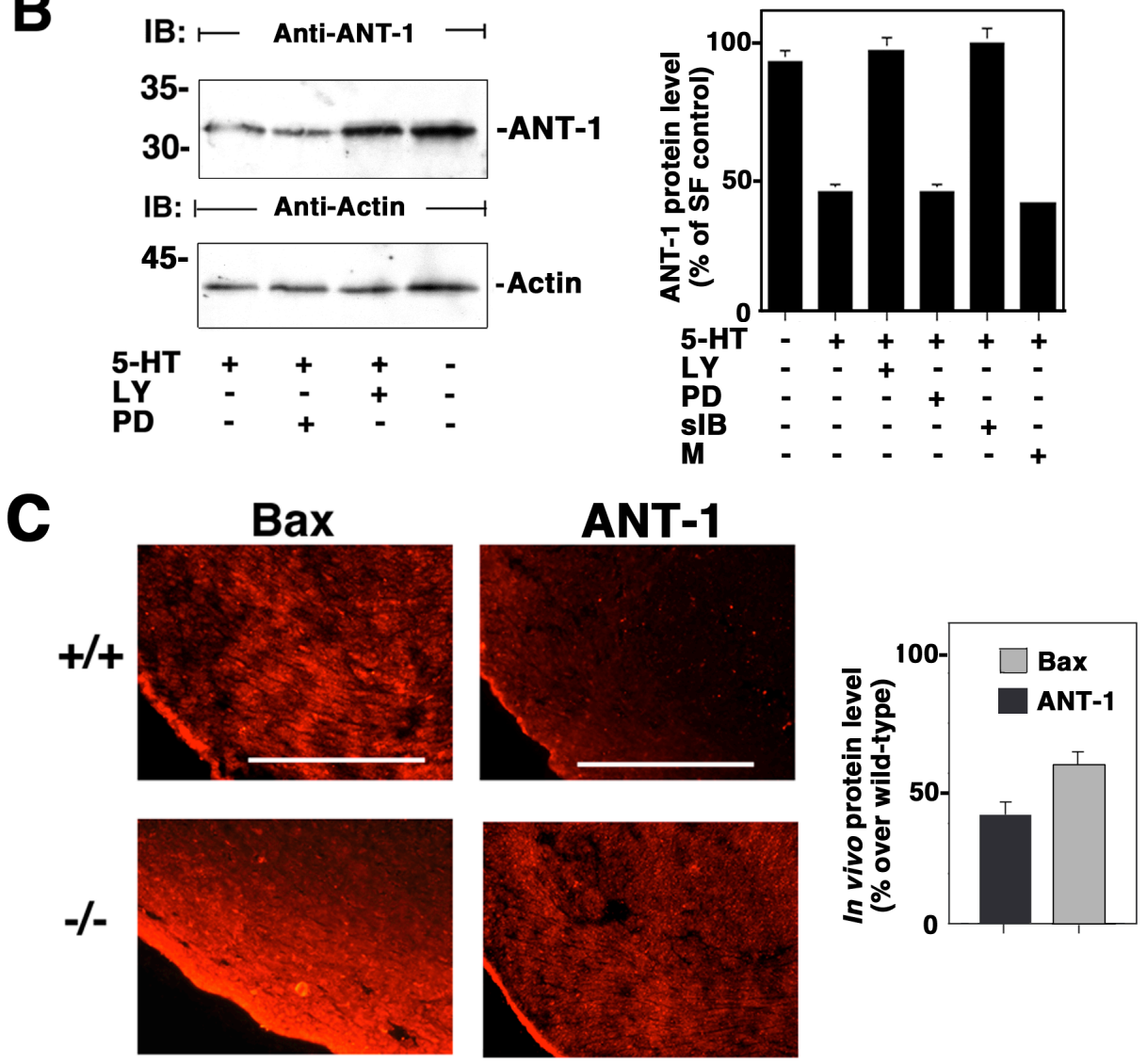

Figure 6. Effects of 5-HT on Bax and ANT-1 levels. A) Reduction of Bax expression by 5-HT. Wild type cardiomyocytes were treated in serum free (SF) medium with $\pm 1 \mu \mathrm{M} 5$-HT and $\pm 10 \mu \mathrm{M} \mathrm{LY}$ 294002 (LY) or $50 \mu \mathrm{M}$ PD-098059 (PD) for 4 days, then extracted and submitted to Western blot analyses to determine the relative quantities of Bax, as described in methods. Phospho-Bad (anti-pBad ser112, ser 155) expression was assessed after restripping of the same blot. The values determined by densitometry using Molecular Dynamics ImageQuant software are shown as a graph \pm S.E.M.. B) Reduction of ANT-1 expression by 5-HT. Cardiomyocytes were treated $\pm 1 \mu \mathrm{M} 5$-HT and $\pm 10 \mu \mathrm{M} \mathrm{LY}$ 294002 or $50 \mu \mathrm{M}$ PD-098059 or \pm Adenovirus sIB (sIB) or \pm Adenovirus GFP (M), then extracted and submitted to Western blot analyses to determine the relative quantities of ANT-1, as described in methods. Actin expression was assessed after restripping of the same blot. The values determined by densitometry using Molecular Dynamics ImageQuant software are shown as a graph. C) Bax and ANT1 expression are increased in knockout mice heart. Bax and ANT-1 expression were evaluated by immunohistochemical staining of cryosections of wild and knockout mice heart. Bars: $500 \mu \mathrm{m}$. The values of staining intensity determined using Molecular Dynamics ImageQuant software are shown as a graph \pm S.E.M.. This experiment is representative of three similar experiments. 


\section{Nebigil figure 7}

\section{A}

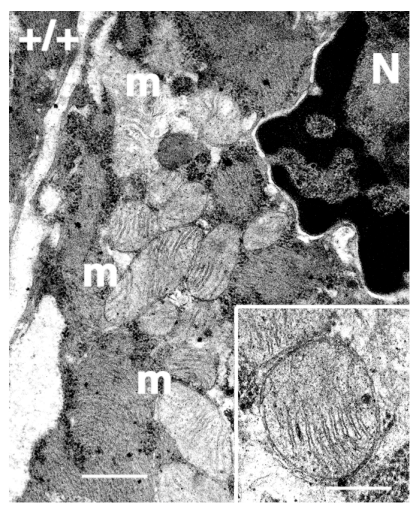

\section{B}

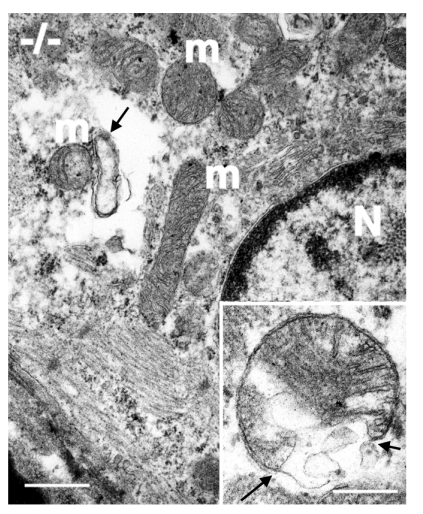

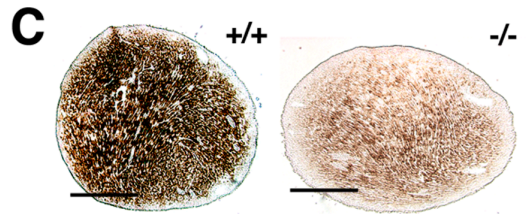

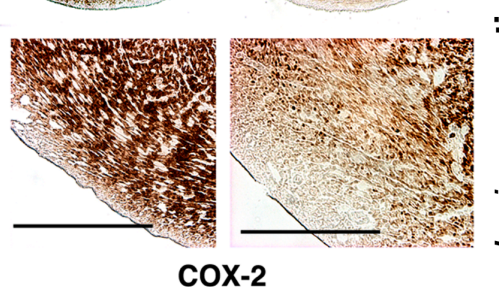

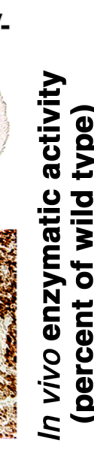

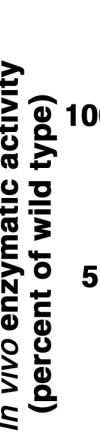

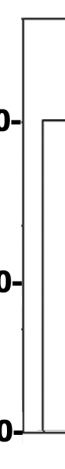

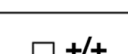

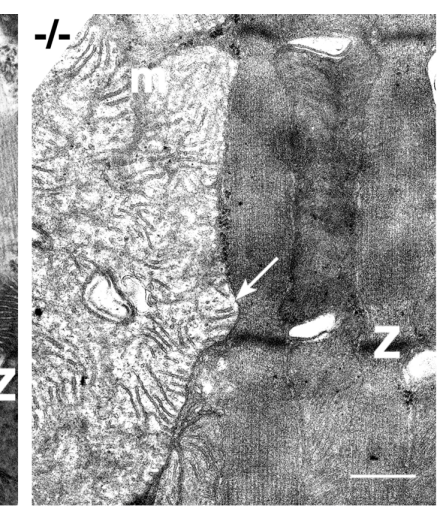
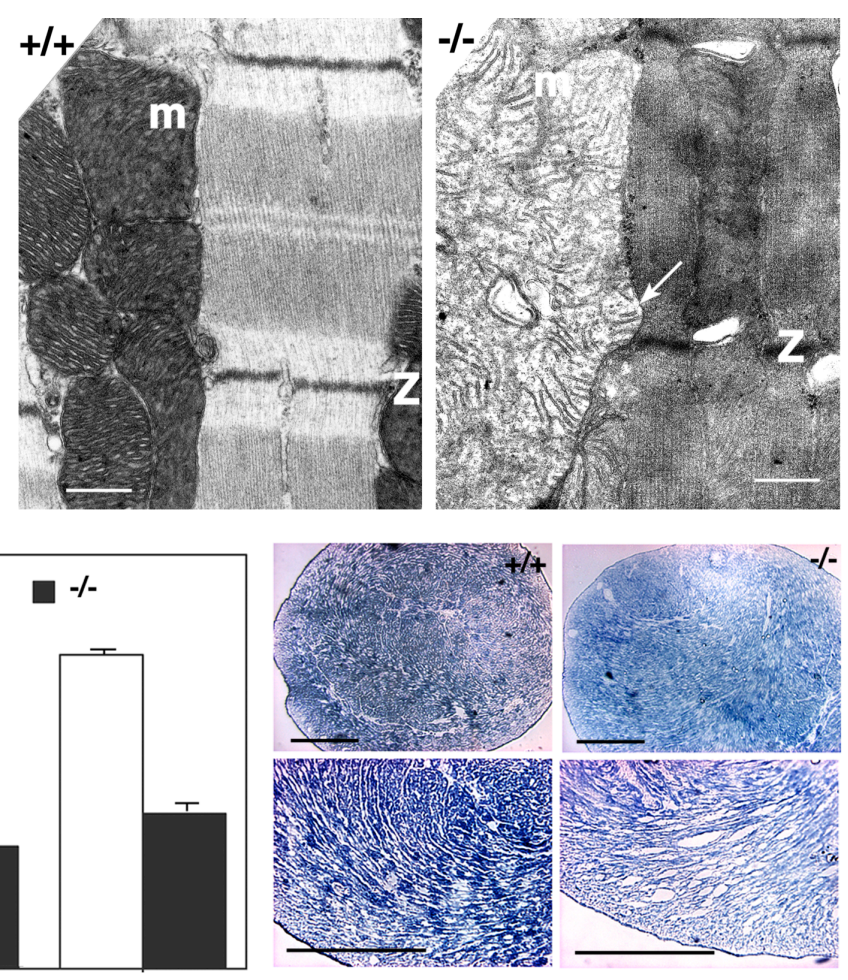

SDH

Figure 7. In vivo mitochondrial defects in $5-H_{2} T_{2 B} R$ knockout mice heart. A) Mitochondrial ultrastructural defects in 5- $\mathrm{HT}_{2 \mathrm{~B}} \mathrm{R}$ knockout newborn mice heart. The analysis of the compact layer of newborn mice heart was performed by transmission electronic microscopy on ultra-thin sections. Mitochondria $(\mathrm{m})$ with apparent intact morphology in wild type heart $(+/+)$ and mitochondria with defective membrane (arrow) are indicated in knockout mice heart (-/-). Bars: $0.5 \mu \mathrm{m}$. Inserts show higher magnification of the mitochondrial defects. Bars: $0.2 \mu \mathrm{m}$. N: nucleus, Z: Z-stripe; B) Mitochondrial ultrastructural defects in $5-\mathrm{HT}_{2 \mathrm{~B}} \mathrm{R}$ knockout adult mice heart. Analysis by transmission electronic microscopy of ultra-thin sections of 6 weeks old mice heart knockout (-/-) and wild type $(+/+)$ in the compact layer was performed. Fused mitochondria $(\mathrm{m})$ with apparent intact outer membrane (arrow) and defective inner membrane are indicated. N: nucleus, Z: Z-stripe; Bars: $0.5 \mu \mathrm{m}$. C) Decreased mitochondrial enzyme activities in the knockout mice heart. Enzymatic histochemical staining for cytoC oxidase (COX-2, brown) and succinate dehydrogenase (SDH, blue) activity were determined in sections of the heart of wild type $(+/+)$ and knockout newborn mice (-/-). Bars: $500 \mu \mathrm{m}$. SDH and COX-2 activities in the mice heart are shown as percent of wild type values. The values of staining intensity were determined using Molecular Dynamics ImageQuant software and shown as a graph \pm S.E.M.. Illustrations are representative of at least 3 separate experiments. 


\section{Nebigil figure 8}

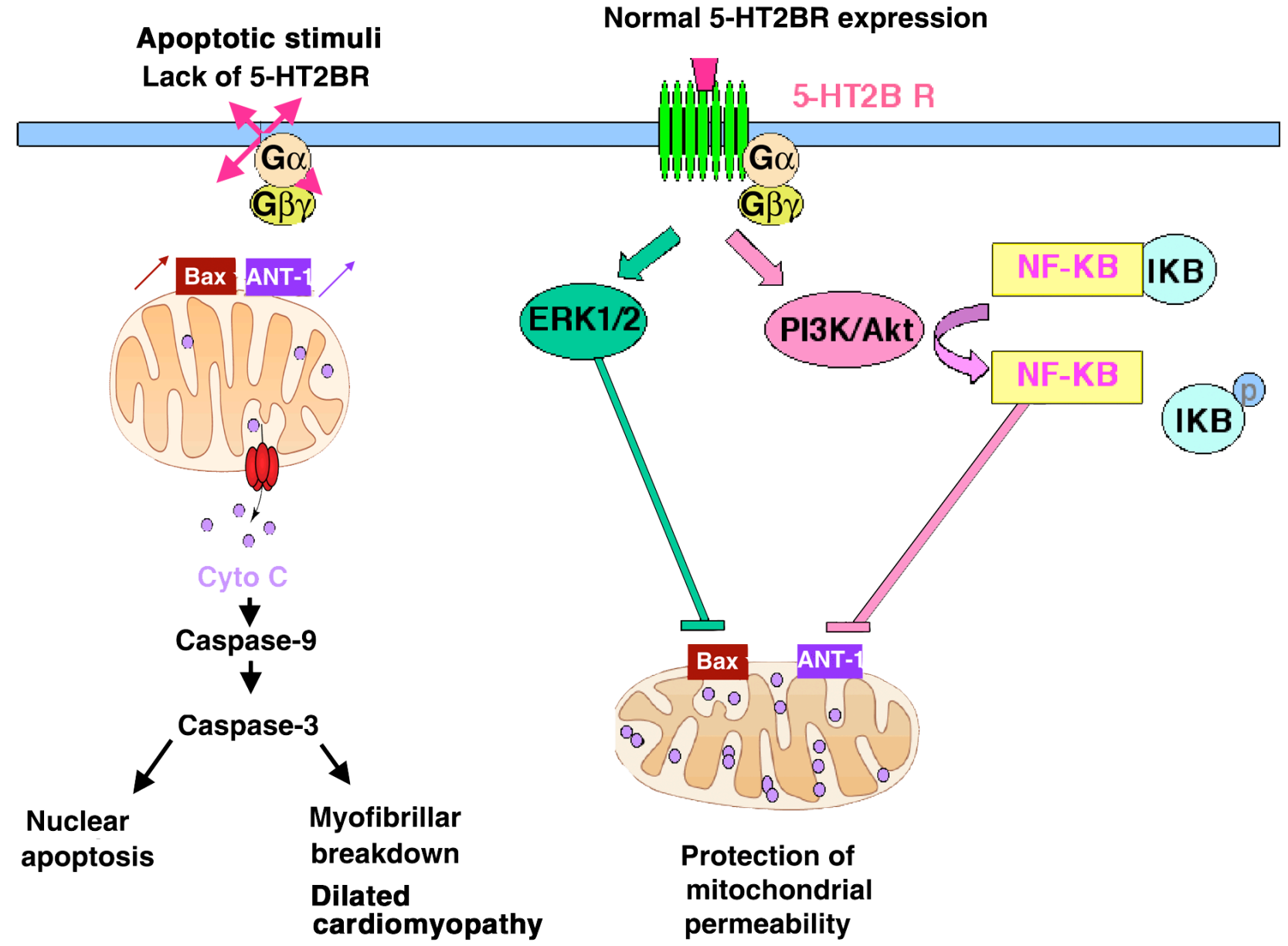

Figure 8. Schematic presentation of 5-HT cytoprotective signaling pathways in cardiomyocytes. 5-HT binding to 5-HT ${ }_{2 \mathrm{~B}} \mathrm{R}$ activates both PI3K/Akt and ERK kinases. ERK activation inhibits serum deprivation-induced Bax expression that controls mitochondrial membrane permeability. Parallel to this pathway, upon Akt activation, phosphorylated IKB-alpha triggers the degradation of IKB-alpha to release NF-KB free. This activation of NF-KB by 5-HT inhibits serum deprivation-induced ANT-1 expression to regulate also mitochondrial permeability. A cross talk between PI3K/Akt/ANT-1 and ERK/ Bax pathways targets mitochondria to prevent cytoC release and caspases activation in the 5$\mathrm{HT}_{2 \mathrm{~B}} \mathrm{R}$ cytoprotective signaling. In the $5-\mathrm{HT}_{2 \mathrm{~B}} \mathrm{R}$ knockout mice as a model of dilated cardiomyopathy, we demonstrate that the Gq-coupled $5-\mathrm{HT}_{2 \mathrm{~B}} \mathrm{R}$ signaling regulates mitochondrial structure and function thereby controlling myofibrillar organization in the heart. 